\title{
CHANGING THE SOCIAL BRAIN: PLASTICITY ALONG MACRO-SCALE AXES OF FUNCTIONAL CONNECTIVITY FOLLOWING SOCIAL MENTAL TRAINING
}

\author{
Sofie L Valk ${ }^{1,2 \Delta}$; Philipp Kanske ${ }^{3,4}$; Bo-yong Park ${ }^{5}$; Seok Jun Hong ${ }^{6-8}$; Anne Böckler- \\ Raettig $^{9}$; Fynn-Mathis Trautwein ${ }^{10}$; Boris C. Bernhardt ${ }^{5}$, Tania Singer ${ }^{11} *$ \\ * joint co-authors
}

1. Otto Hahn Group Cognitive Neurogenetics, Max Planck Institute for Human Cognitive and Brain Sciences, Leipzig, Germany; 2. INM-7, FZ Jülich, Jülich, Germany; 3. Clinical Psychology and Behavioral Neuroscience, Faculty of Psychology, Technische Universität Dresden, Dresden, Germany; 4. Max Planck Institute for Human Cognitive and Brain Sciences, Leipzig, Germany; 5. Multimodal Imaging and Connectome Analysis Lab, McConnell Brain Imaging Centre, Montreal Neurological Institute and Hospital, McGill University, Montreal, Quebec, Canada; 6. Center for the Developing Brain, Child Mind Institute, NY, USA; 7. Center for Neuroscience Imaging Research, Institute for Basic Science, Suwon, South Korea; 8. Department of Biomedical Engineering, Sungkyunkwan University, Suwon, South Korea; 9. Department of Psychology, Leibniz University Hannover, Germany; 10. Klinik für Psychosomatische Medizin und Psychotherapie, Universitäts Klinikum Freiburg, Freiburg, Germany; 11. Social Neuroscience Lab, Max Planck Society, Berlin, Germany

\footnotetext{
${ }^{\Delta}$ Correspondence to Sofie L Valk
}

Email:valk@cbs.mpg.de

Keywords: social cognition; ToM; empathy; compassion; social emotions; attention, mental training; plasticity; functional connectivity; connectome; gradients 
Valk et al. | Changing the social brain

\section{AbSTRACT}

2 Despite the importance of our ability to understand the thoughts and feelings of others, the 3 social brain remains incompletely understood. Here, we studied the plasticity of social brain 4 function in healthy adults following the targeted training of attention-mindfulness, socio5 affective, and socio-cognitive skills for 9 months. All participants were followed with 6 repeated multimodal neuroimaging and behavioral testing. Longitudinal analyses of 7 functional networks indicated marked and specific reorganization following mental training. 8 Socio-cognitive training resulting in an increased integration of multiple demand and default

9 mode regions whereas attention-mindfulness resulted in their segregation. Socio-affective 10 training resulted in an increased functional integration of ventral attention network with these 11 regions. Changes in functional network organization were robust after varying analysis 12 parameters, and predictive of change in behavioral markers of compassion and perspective13 taking. Our results advance the understanding of the social brain, describing its intrinsic 14 functional organization and reorganization following mental training. 
bioRxiv preprint doi: https://doi.org/10.1101/2020.11.11.377895; this version posted June 7, 2021. The copyright holder for this preprint (which

was not certified by peer review) is the author/funder, who has granted bioRxiv a license to display the preprint in perpetuity. It is made

Valk et al. | Changing the social brain

\section{INTRODUCTION}

2 Humans have unique social skills that enhance cooperation and survival (Dunbar, 1998;

3 Ochsner and Lieberman, 2001). These social capacities can largely be divided into several

4 components (Schurz et al., 2020a; Singer, 2006): Firstly, socio-affective (or emotional-

5 motivational) abilities allow us to share feelings with others, and may give rise to compassion

6 and prosocial motivation (Batson, 2009; de Vignemont and Singer, 2006; Eisenberg and

7 Fabes, 1990). Secondly, a socio-cognitive system gains access to beliefs and intentions of

8 others, a skill also referred to as Theory of Mind (ToM) or mentalizing (Frith and Frith, 2006;

9 Saxe and Kanwisher, 2003; Singer, 2006). Finally, there is evidence for a role of attention,

10 action observation, and mindfulness as important auxiliary functions of these social aptitudes,

11 which underlie self-other distinctions and awareness (Craig, 2009; Kleckner et al., 2017;

12 Tomasello, 1995). Together, these human capacities combine externally and internally

13 oriented cognitive and affective processes and reflect both focused and ongoing thought

14 processes (Barrett, 2017; Chun et al., 2011; Murphy et al., 2019; Sormaz et al., 2018;

15 Turnbull et al., 2020). However, to what extent these processes are malleable following

16 targeted training is incompletely understood.

17 Previous functional neuroimaging studies have identified dissociable brain networks involved 18 in these components of social cognition, which somewhat recapitulate large-scale functional 19 networks also seen in the resting brain, notably the ventral attention network (VAN) and 20 paralimbic networks in the case of socio-affective processing (Alcala-Lopez et al., 2018; 21 Lamm et al., 2011; Schurz et al., 2020a), the default mode network (DMN) in the case of ToM (Alcala-Lopez et al., 2018; Schurz et al., 2020a), and multiple demand network (MDN) in the case of attention and action observation (Assem et al., 2020; Schurz et al., 2020a). Indeed, tasks probing empathy consistently elicit functional activations in anterior insula, supramarginal gyrus, and midcingulate cortex (Singer, 2006; Singer and Lamm, 2009; Singer et al., 2004), while ToM paradigms activate the DMN regions such as medial frontal cortex, temporo-parietal junction, and superior temporal sulcus (Bzdok et al., 2012; Saxe and Kanwisher, 2003; Schurz et al., 2020a). Conversely, attention and action observation activate inferior parietal and lateral frontal and anterior insular cortices (Corbetta et al., 2008; Corbetta and Shulman, 2002; Trautwein et al., 2016). At the same time, it has been shown that the capacity to understand the feelings and thoughts of others in naturalistic settings are supported by multiple processes and consequently implicate combinations of distributed brain networks (Alcala-Lopez et al., 2018; Chang et al., 2015; Pessoa, 2014; Raz et al., 2016; Schaafsma et al., 2015; Schilbach et al., 2013; Schurz et al., 2020b; Zaki et al., 2009). Thus, social cognitive processing can be understood as a hierarchical phenomenon, including automatic and controlled functional processes (de Waal, 2012; Preston and de Waal, 2002; Schurz et al., 2020b; Singer, 2006). However, a causal relationship between brain function and differentiable processes underlying social behavior has not been investigated.

Expanding cross-sectional association studies, longitudinal investigations can reveal links 40 between social skills and the human brain, for example by targeted mental training designs. 41 Only few previous studies have addressed longitudinal mental training effects in the domain 42 of social cognition. While these have generally suggested changes in behaviour and MRI43 based measures of brain structure and function (Pernet et al., 2021; Tang et al., 2015), sample 
1 sizes were relatively modest and training intervals short. Moreover, few studies have 2 compared different practices or focussed on different social skills specifically. Our work was 3 realized in the context of the ReSource study (Singer et al., 2016), a large-scale study 4 involved a targeted training of attention-mindfulness (Presence module), followed by socioaffective (Affect module) and socio-cognitive/ToM training (Perspective module) over the course of nine months. Whereas Presence aimed at initially stabilizing the mind and nurturing introspective abilities, the Affect and Perspective modules focussed on nurturing social skills such as empathy, compassion, and perspective taking on self and others. Based on the ReSource sample, our group could previously show differentiable change in cortical thickness following these modules, illustrating structural plasticity of the social brain (Valk et al., 2017). However, it remains unknown how targeted training of interoceptive and attentional processes, socio-affective competences, and socio-cognitive skills relative to changes in brain

13 functional organization.

The overlap between functional activation patterns during specific social cognition paradigms and large-scale functional systems at rest implicates that these functional processes are underpinned by the intrinsic organization of the cerebral cortex (Mesulam, 1998). This organisation enables the spatial integrating and segregating of different cortical networks, and has been increasingly conceptualized to run along continuous dimensions, also referred to as connectivity gradients (Huntenburg et al., 2018; Margulies et al., 2016; Murphy et al., 2019; Paquola et al., 2019). Reliably identifiable from resting-state functional connectivity data, such gradients can be used to compactly describe neural organization (Haak and Beckmann, 2020; Haak et al., 2018; Hong et al., 2020; Margulies et al., 2016; Shine et al., 2019). For example, the principal gradient places transmodal association networks such as the DMN and paralimbic networks at a maximal distance from sensory and motor regions (Huntenburg et al., 2018; Margulies et al., 2016; Murphy et al., 2019). This segregation may allow association cortices to take on functions only loosely constrained by the environment, which likely facilitates the formation of abstract representations and transformations required for socio-cognitive and socio-affective processing (Smallwood et al., 2021). Complementing this sensory-transmodal hierarchy, the second gradient reflects a visual-somatomotor differentiation and the third gradient differentiates the MDN from the rest of the brain (Turnbull et al., 2020). Social processes likely have a differential positioning along these gradients, with ToM possibly being associated with transmodal networks such as the DMN (Margulies et al., 2016). Attention may reflect more external focus (Murphy et al., 2019), whereas socio-affective processes may include both alerting, emotionally salient, stimuli from the environment, and more abstract forms of ongoing thought and emotions (Schurz et al., 2020b). Effective connectivity studies in social cognition have furthermore shown that, depending on the task, different transmodal brain networks are either integrated and segregated (Barrett and Satpute, 2013; Betzel et al., 2016; Dajani and Uddin, 2015; Schurz et al., 2020a; Shine et al., 2019). For example, complex and demanding ToM tasks often involve an integration of distributed brain networks, such as the DMN and frontal parietal network (Schurz et al., 2020a; Shine et al., 2016). Conversely, segregation of brain networks may relate to a temporally and hierarchically reduced depth of processing, and may potentially be 
Valk et al. | Changing the social brain

1 the precise mapping of social brain functions to intrinsic organizational axes is not understood 2 to date.

3 Capitalizing on the longitudinal Resource study (Singer et al., 2016), here we studied 4 functional network plasticity of the social brain. In particular (Singer et al., 2016), we 5 examined functional network reorganization following the three training modules i.e., 6 Presence (promoting attention and interoceptive awareness, resembling mindfulness-based 7 interventions (Kabat-Zinn, 1990)), Affect (focusing on socio-affective capacities, such as 8 compassion, gratitude, dealing with difficult emotions), and Perspective (focusing on socio9 cognitive skills, such as perspective-taking on self and others/ToM as well as metacognition).

10 We sought to specifically assess plasticity of task-based functional networks contributing to 11 attention, socio-affective, and socio-cognitive skills (Kanske et al., 2015; Trautwein et al., 12 2016) in an intrinsic coordinate system spanned by the first three functional connectivity 13 gradients, together describing functional network integration and segregation. We 14 hypothesized that the training of these social skills would result in dissociable functional 15 reorganization. In addition to assessing the reorganization of brain functional architecture, we 16 assessed associations to behavioral change in attention, compassion, and ToM markers using 17 machine learning with cross-validation. A series of additional analyses evaluated the 18 robustness of our findings with respect to analysis parameter choices and further 19 contextualized findings. 
bioRxiv preprint doi: https://doi.org/10.1101/2020.11.11.377895; this version posted June 7, 2021. The copyright holder for this preprint (which

was not certified by peer review) is the author/funder, who has granted bioRxiv a license to display the preprint in perpetuity. It is made

Valk et al. | Changing the social brain

\section{RESUlts}

2 Changes in functional eccentricity following the targeted training of social skills

3 We analyzed resting-state as well as task-based fMRI and behavioral data from a large-scale

4 mental training intervention, the ReSource Project (Singer et al., 2016). For details, see

5 http://resource-project.org and the preregistered trial

6 https://clinicaltrials.gov/ct2/show/NCT01833104.

7 We first derived task-based fMRI activation patterns associated with (i) attention, based on a

8 Cued-flanker task (Trautwein et al., 2016), (ii) socio-affective functions, such as empathy and

9 compassion, based on the affect contrast in the EmpaTom task (Kanske et al., 2015), and (iii)

10 socio-cognitive functioning, based on the ToM contrast of the EmpaTom (Kanske et al.,

11 2015) in the current sample. These networks describe differentiable combinations of

12 functional communities associated with attention, socio-emotional, and socio-cognitive task-

13 activations, including MDN, ventral attention network (VAN), and DMN (Supplementary

14 Results). To compactly describe large-scale functional brain organization, we reduced the

15 dimensionality of the resting-state fMRI connectomes using previously utilized techniques

16 (Vos de Wael et al., 2020). The identified eigenvectors are spatial gradients describing

17 continuous axes of connectivity space (Coifman et al., 2005; Margulies et al., 2016; Vos de

18 Wael et al., 2020). Gradients of each individual were aligned to a template based on the

19 Human Connectome Project dataset (Van Essen et al., 2013; Vos de Wael et al., 2020). For

20 each vertex, we calculated its distance from the center of the gradient coordinate system

21 formed by G1, G2, and G3 for each individual. This eccentricity captured vertex-wise

22 intrinsic functional integration (low eccentricity) and segregation (high eccentricity) in a

23 single scalar value (Bethlehem et al., 2020; Coifman et al., 2005; Park et al., 2020).

24 Eccentricity indeed correlated positively $(r>0.5, p<0.001$ when controlling for spatial

25 autocorrelation) with network clustering coefficient and characteristic path length, supporting

26 that it captured segregation and integration of large-scale networks (Supplementary

27 Results). Highest segregation was observed in visual and sensory-motor networks, while

28 ventral attention and limbic networks were closest to the center of the space (Menon and

29 Uddin, 2010). Calculating eccentricity scores of the activations at baseline (Figure 1C),

30 attention networks had a lower eccentricity than both social networks (both $\mathrm{p}<0.001$ ).

31 We then examined how functional organization of the different social networks changed

32 following their targeted training. Resource participants were randomly assigned to two

33 training cohorts $(\mathrm{TC} 1, \mathrm{~N}=80 ; \mathrm{TC} 2, \mathrm{~N}=81)$ and underwent a 9-month training consisting of

34 three sequential training modules with weekly group sessions and daily exercises, completed

35 via cell-phone and internet platforms (Figure 1, Table 1-3, Materials and Methods and

36 Supplementary Materials for more details). TC1 and TC2 underwent the latter two modules in

37 different order (TC1: Affect $\rightarrow$ Perspective; TC2 Perspective $\rightarrow$ Affect) to serve as active control

38 groups for each other (Figure 1C). Additionally, a matched test-retest control cohort did not

39 undergo any training ( $\mathrm{RCC}, \mathrm{N}=90$ ), but was followed with the same measures as TC1 and

40 TC2, as well as an active control group (TC3; $\mathrm{N}=81$ completed three months of Affect training

41 only). All participants were measured at the end of each three-month module $\left(\mathrm{T}_{1}, \mathrm{~T}_{2}, \mathrm{~T}_{3}\right)$

42 using 3T MRI and behavioral measures that were identical to the baseline $\left(\mathrm{T}_{0}\right)$ measures. 
bioRxiv preprint doi: https://doi.org/10.1101/2020.11.11.377895; this version posted June 7, 2021. The copyright holder for this preprint (which was not certified by peer review) is the author/funder, who has granted bioRxiv a license to display the preprint in perpetuity. It is made available under aCC-BY-NC-ND 4.0 International license.

Valk et al. | Changing the social brain

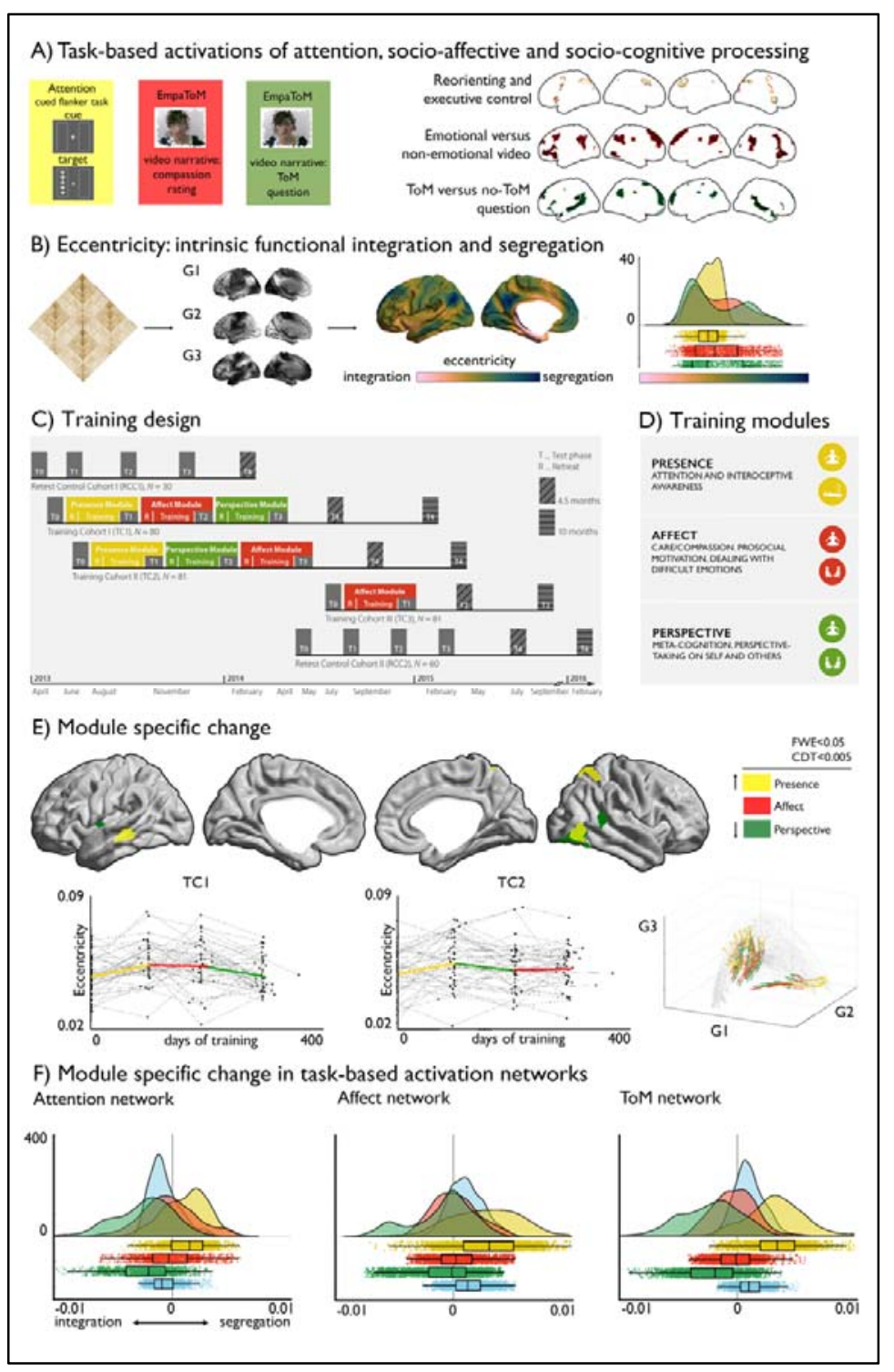

Figure 1. Functional eccentricity alterations of the social brain following mental training. A). Functional localizers (Kanske et al., 2015; Trautwein et al., 2016) and their mappings projected on the cortex; B) Vertexlevel eccentricity from rs-fMRI by combining the first three gradients (G1-G3); middle: vertex-wise eccentricity and right: eccentricity of task-based social networks; C). Training design of the ReSource study; D). Training modules; E). upper panel: Differential change in 3D gradient distance following mental training, lower panel left: Average change in overlapping clusters associated with eccentricity change in Presence and Perspective (light green) following Presence (yellow), Affect (red), and Perspective (green) in TC1 and TC2; lower panel right: visualization of local eccentricity changes as a function of $3 \mathrm{~d}$ gradient space. Arrows indicate direction of change; F). Changes in average network eccentricity, colored by training: Presence (yellow), Affect (red), Perspective (green), and retest controls (light blue). Whole brain findings are corrected for multiple comparisons at $\mathrm{p}_{\mathrm{FWE}}<0.005$, two-tailed.

13 Our main analysis tracked longitudinal change in functional eccentricity and each gradient separately (G1-G3) using mixed-effects models (Dale et al., 1999). We observed marked eccentricity changes following Presence and Perspective. Presence training resulted in increased eccentricity of bilateral temporal and right superior parietal areas (family-wise error corrected $\mathrm{p}$-value, $\mathrm{p}_{\mathrm{FWE}}<0.05$ ), indicating increased segregation of these regions. Perspective training resulted in decreased eccentricity of right temporal regions, together with left insular 
1 cortices $\left(\mathrm{p}_{\mathrm{FWE}}<0.05\right)$. We observed no significant eccentricity change following Affect

2 training. Trajectories were similar in TC1 and TC2 (Figure S2).

3 Following, we evaluated training-related alterations in the task-derived functional networks.

4 We observed increases in eccentricity of the attention $(\mathrm{t}=2.43, \mathrm{p}=0.05)$ and socio-cognitive

5 network $(\mathrm{t}=3.24, \mathrm{p}=0.01)$ in following Presence training, whereas both the attention $(\mathrm{t}=-2.42$,

$6 \mathrm{p}=0.05)$ and socio-cognitive network $(\mathrm{t}=-2.91, \mathrm{p}=0.02)$ showed decreased eccentricity

7 following Perspective training (Figure 2D). These findings indicated that functional

8 connectivity within task-based attention and socio-cognitive network becomes more

9 dissimilar from other networks following the training of mindfulness-attention during

10 Presence training, whereas the training of socio-cognitive skills during Perspective leads to

11 increased similarity of attention and socio-cognitive networks with the rest of the

12 connectome. Post-hoc analysis confirmed that eccentricity changes in task-based functional

13 networks were comparable within TC1 and TC2 separately (Figure S2), relative to RCC

14 (Figure S3) and when controlling for global signal (Figure S4). Studying changes within

15 large-scale functional communities (Yeo et al., 2011), we found similar patterns indicating

16 differentiable shifts in integration and segregation after Presence and Perspective training

17 (Supplementary Results).

18 Relation to alterations in connectome gradient embedding

19 Having established changes in overall patterns of segregation and integration following

20 ReSource training, we studied alterations within the first three large-scale gradients (Figure 212 2).

As in prior work (Margulies et al., 2016), the first gradient (G1) differentiated sensory-motor from transmodal systems, such as the default mode network (DMN). At baseline, attention networks had a lower position relative to both socio-affective $(\mathrm{p}<0.001)$ and socio-cognitive $(\mathrm{p}<0.001)$ networks. The two latter networks both occupied the transmodal end of G1. Within G1, we found increases after Affect along G1 in right supramarginal gyrus and right middle 27 insula $\left(\mathrm{p}_{\mathrm{FWE}}<0.05\right)$.

The second gradient $(\mathrm{G} 2)$ ran from sensory-motor to visual networks. For G2, attention networks were lower than socio-affective networks $(\mathrm{p}<0.003)$, but higher than socio-cognitive networks $(p<0.001)$. Socio-affective networks were at a higher position on G2 relative to socio-cognitive networks $(\mathrm{p}<0.001)$. Studying alterations following mental training along $\mathrm{G} 2$, we found decreases in right posterior insula extending to superior temporal gyrus $\left(\mathrm{p}_{\mathrm{FWE}}<0.05\right)$ following Presence and decreases in right orbitofrontal cortex $\left(\mathrm{p}_{\mathrm{FWE}}<0.05\right)$ following 34 Perspective.

The third gradient (G3) differentiated the multiple-demand network, MDN (Duncan, 2010), from the rest of the brain. For G3, attention networks had a higher loading than socioaffective networks $(\mathrm{p}<0.001)$, which, in turn, had a higher loading than socio-cognitive networks $(\mathrm{p}<0.001)$, indicating a clear differentiation of all three networks along this gradient. Within G3, we observed decreases in left inferior temporal and occipital regions $\left(\mathrm{p}_{\mathrm{FWE}}<0.001\right.$ ) following Affect. We did not observe significant change in task-based networks along gradient 
bioRxiv preprint doi: https://doi.org/10.1101/2020.11.11.377895; this version posted June 7, 2021. The copyright holder for this preprint (which was not certified by peer review) is the author/funder, who has granted bioRxiv a license to display the preprint in perpetuity. It is made available under aCC-BY-NC-ND 4.0 International license.

Valk et al. | Changing the social brain

1 changes in Affect along G1 were consistently observed in both cohorts (Supplementary

2 Results).

3 In sum, we could show consistent and divergent functional network plasticity of key regions

4 in the MDN, VAN, and DMN following the training of attention-mindfulness, socio-affect

5 and socio-cognition.

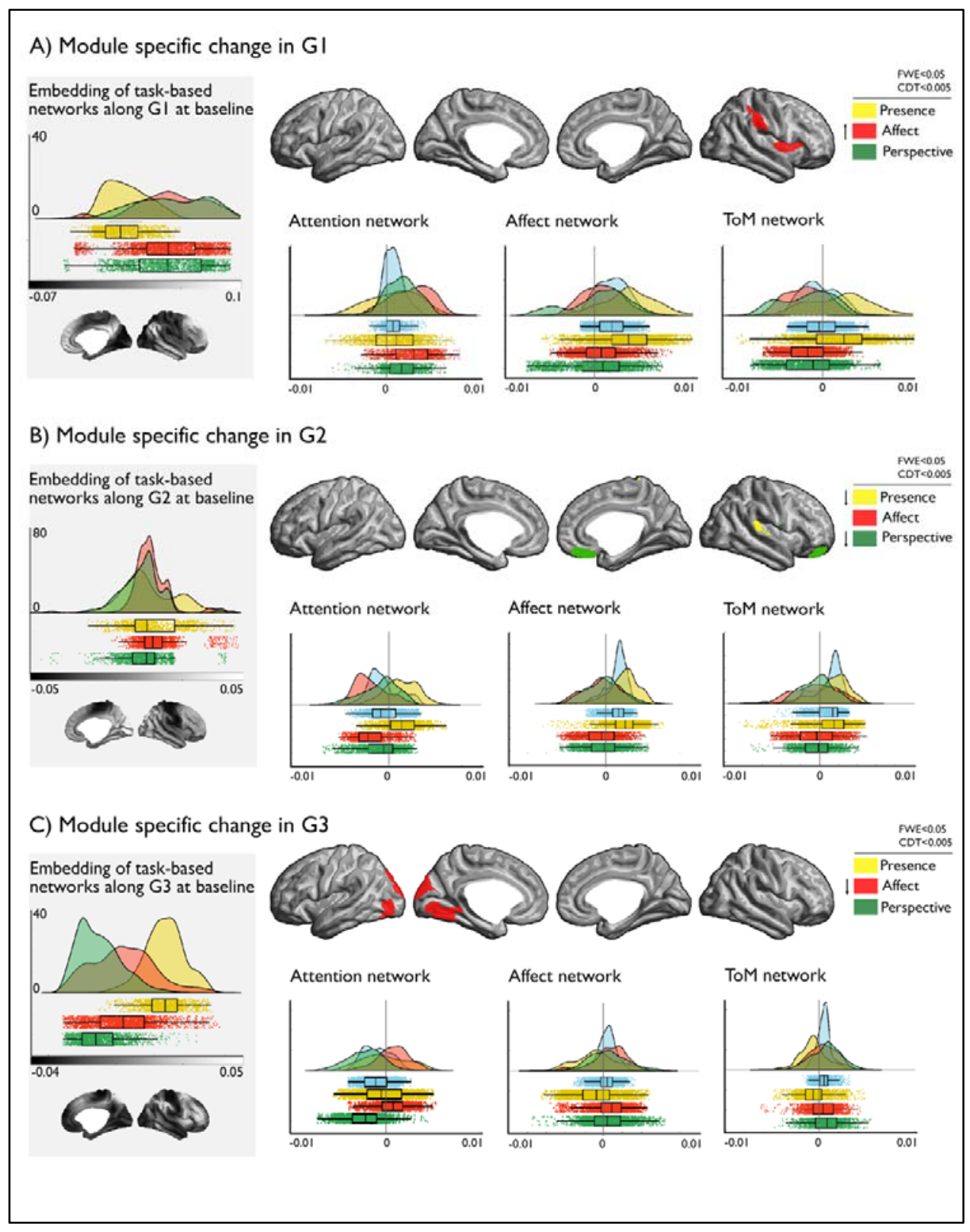

7 Figure 2. Functional gradient alterations of the social brain following mental training. A-C) Left panel (grey): Embedding of task-based networks along G1-G3. upper panel: Changes in G1-G3 respectively, arrows in the panel next to the color-boxed indicate increase of decrease; lower panel: visualization of task-based networkspecific changes in each gradient. Colors indicate the training module (yellow=Presence; red=Affect;

11 green=Perspective) and retest controls (light blue). Whole brain findings are corrected for multiple comparisons 12 at $\mathrm{p}_{\mathrm{FWE}}<0.005$, two-tailed.

13 Associations between functional network reconfiguration and behavioral change 
bioRxiv preprint doi: https://doi.org/10.1101/2020.11.11.377895; this version posted June 7, 2021. The copyright holder for this preprint (which

was not certified by peer review) is the author/funder, who has granted bioRxiv a license to display the preprint in perpetuity. It is made available under aCC-BY-NC-ND 4.0 International license.

Valk et al. | Changing the social brain

1 Last, we evaluated whether the above alterations in functional eccentricity following mental 2 training could predict behavioral changes following the Resource training. We first replicated 3 previous observations of module-specific behavioral change (Trautwein et al., 2020) in the 4 current sample with fMRI data available. Attention scores increased during Presence relative 5 to the other modules $(\mathrm{t}=3.837, \mathrm{p}<0.001)$ and to RCC $(\mathrm{t}=3.193, \mathrm{p}<0.001)$. Compassion scores 6 increased following Affect relative to the other modules $(\mathrm{t}=3.361, \mathrm{p}<0.001)$ and to RCC $7 \quad(\mathrm{t}=3.695, \mathrm{p}<0.001)$. Finally, ToM scores were marginally increased during Perspective 8 relative to the other modules $(\mathrm{t}=1.600, \mathrm{p}=0.055)$ and $\mathrm{RCC}(\mathrm{t}=1.588, \mathrm{p}=0.056)$.

9 Supervised learning (elastic net, 10 components, 5-fold cross validation, 5000 repetitions 10 (Chang et al., 2015)) was utilized to predict behavioral change from the three gradients combined. G1-G3 combined could predict compassion (prediction - outcome $\mathrm{r}=0.20$, mean absolute error (MAE): 2.44, $\mathrm{p}=0.046$ ) and ToM scores ( $\mathrm{r}=0.24$, MAE:2.36, $\mathrm{p}=0.02$ ) change. Binning change scores in 10 bins improved predictions relative to using the raw change scores in both compassion and ToM, yet change in attention was not predictable $(\mathrm{r}=-0.03)$ (Supplementary Results). Features were selected in anterior and inferior temporal, limbic, and visual cortex, and related predominantly to G2 for compassion, particularly with lower weights on attention and higher weights on socio-cognitive networks. Conversely, features predictive of ToM change related to a dissociable pattern between attention and sociocognitive network weights in G3.

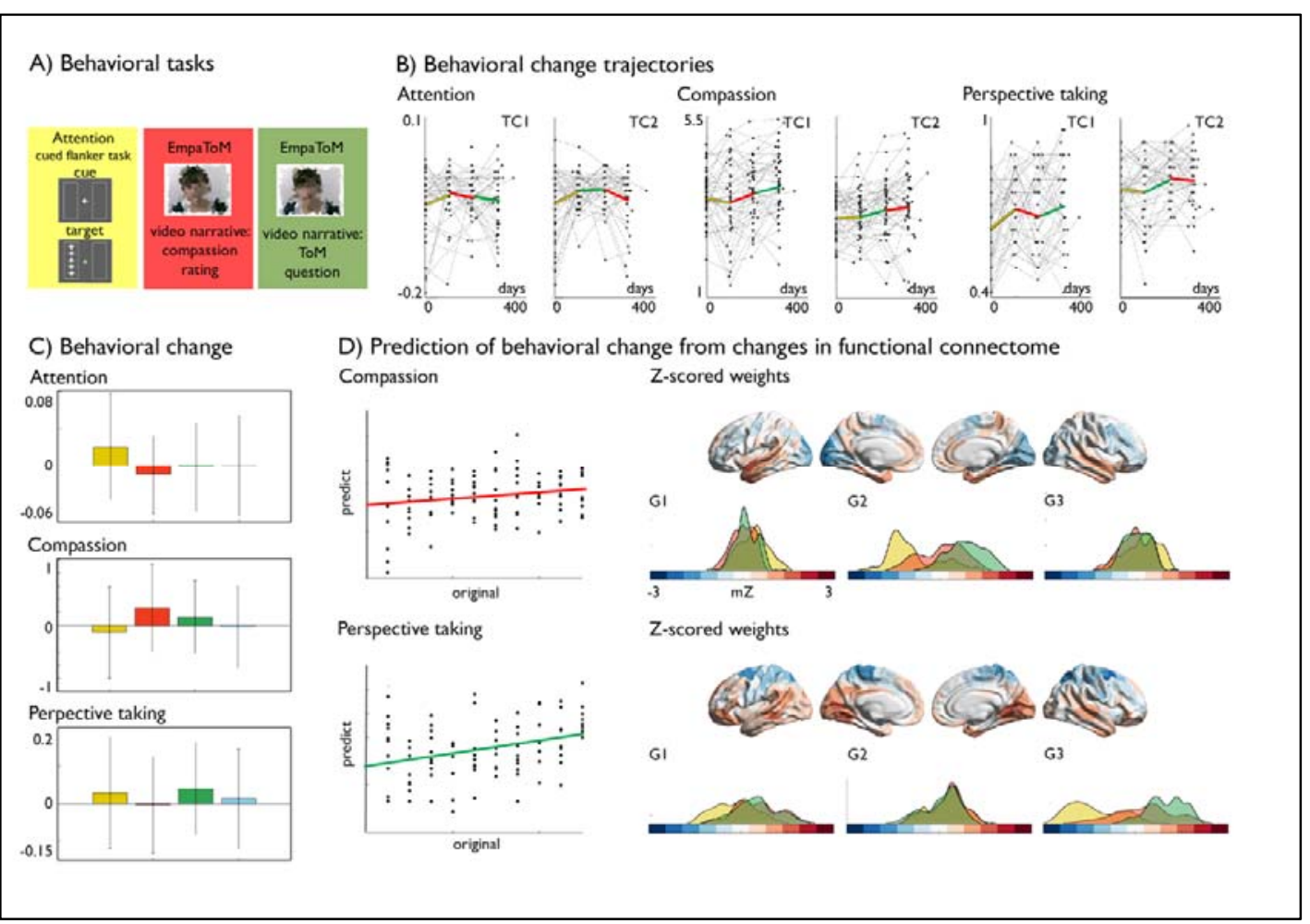

Figure 3. Association between changes in functional embedding and changes in behaviour. A). Behavioral tasks that measured attention, compassion, and perspective-taking; B). Behavioral measurements in TC1 and TC2 across time-points (Trautwein et al., 2020); C). Behavioral change across modules; D). Prediction behavior change across time-points. left: scatter of predicted versus original scores; right upper: average bootstrapped zscore; right lower: average bootstrapped z-score within task-based network per gradient dimension. 
Valk et al. | Changing the social brain

\section{$1 \quad$ Robustness analyses}

2 Various additional analysis indicated robustness of our findings (Supplementary Results);

- To validate our vertex-level approach, we additionally computed network-level index of segregation and integration; the dispersion within as well as distance between taskbased fMRI activations in 3D gradient space (Bethlehem et al., 2020), respectively reflective of segregation within and between networks. Using these network-level metrics we observed similar patterns of network integration and segregation following the mental training modules.

- Taking a graph theoretical approach to integration and segregation, using clustering coefficient and path length (Rubinov and Sporns, 2010), we could confirm differentiable patterns of integration and segregation in task-based functional networks after Presence and Perspective modules.

- We observed similar results when performing global signal regression, indicating the observed patterns of intrinsic functional integration and segregation did not relate to global signal changes as a function of training.

- We observed no significant association with change in task-unrelated thoughts when evaluating change in post-scan thought probes after each mental training block, suggesting the contents of thought during resting state assessment did not systematically vary as a function of mental training.

- As the task-based activations within the current sample were key to our analysis, we performed extensive decoding to leverage the dissociability of the functional activations associated with attention, socio-affect, and socio-cognitive tasks in the present sample with canonical functional-networks, transcriptomic expression, and meta-analytical task space. These measures provide further contextualization of our sample specific networks, and as such help to interpret the sample and metric-specific networks. These additional analyses confirmed the observed task-based networks were consistently different across samples and approaches. 
bioRxiv preprint doi: https://doi.org/10.1101/2020.11.11.377895; this version posted June 7, 2021. The copyright holder for this preprint (which

was not certified by peer review) is the author/funder, who has granted bioRxiv a license to display the preprint in perpetuity. It is made

Valk et al. | Changing the social brain

\section{DISCUSSION}

2 Assessing longitudinal change following mental training provided evidence for the 3 interrelation of intrinsic functional brain organization and social and attentional functions.

4 Particularly, our findings show functional segregation of regions in the multiple demand 5 network (MDN) and default mode network (DMN) following Presence training, indicating 6 that these networks differentiated from the rest of the cortex. Conversely, Perspective training 7 resulted in their functional integration. Affect resulted in marked alterations of functional 8 organization of regions in the ventral attention network (VAN) along the first gradient 9 specifically, reflecting an increased integration of these regions with MDN and DMN 10 networks. Second, we could predict changes in compassion and ToM scores based on cooccurring changes in large-scale functional organization, suggesting behavioral relevance of functional network alterations following mental training. In sum, our study showed that the concerted training of social skills results in dissociable changes in the functional connectome. Although our work focused on healthy adults ranging from 20 to 55 years of age, our findings overall support the possibility that targeted mental training can enhance social skills and lead to co-occurring functional network reconfigurations. These findings could inform future efforts to develop interventions aimed at cultivating the understanding of thoughts and feelings of others.

Higher cognition reflects a balance between parallel processing in an integrated architecture versus more segregated hierarchical processing (Bertolero et al., 2015; Mesulam, 1998; Schurz et al., 2020a; Schurz et al., 2020b). Analyzing task-derived fMRI networks involved in social and attentional processes at baseline, we could show that these networks were positioned differently in a coordinate system spanned by the first three functional gradients. Echoing prior work in young adults (Margulies et al., 2016), the principal gradient ran from unimodal to transmodal systems such as the DMN. This axes aligns with classic notions of cortical hierarchy (Margulies et al., 2016), axes of microstructural differentiation (Huntenburg et al., 2017; Paquola et al., 2020b; Paquola et al., 2019) and cortical evolution, with heteromodal regions undergoing recent expansions in the human lineage (Valk et al., 2020; $\mathrm{Xu}$ et al., 2020). In our findings, socio-affective and socio-cognitive functional activations were located at the higher end of this functional hierarchy stretching from perception/action to flexible cognition. Functions key to social cognition such as ToM are often co-localized with, if not equal to, heteromodal association systems such as the DMN (Alcala-Lopez et al., 2018; Alcala-Lopez et al., 2019; Alves et al., 2019; Kernbach et al., 2018). The DMN is thought to integrate multiple streams of information (Margulies et al., 2016; Paquola et al., 2020a; Turnbull et al., 2020), coordinating internal and external information (Frith and Frith, 2003; Murphy et al., 2018; Murphy et al., 2019; Schurz et al., 2020b), and supporting predictive processing (Chanes and Barrett, 2016). Conversely, attention was associated with the middle of this axes, indicating its function to bridge sensory and integrative processing. Notably, task-based networks involved in attention, socio-affective, and socio-cognitive skills were linearly ordered along the third gradient, which dissociates the MDN from rest of the brain, with attention closest to the MDN and socio-cognitive skills closest to the DMN. Unlike the DMN, the MDN engages in preferentially in externally oriented tasks (Buckner et al., 2008; Margulies et al., 2016). Recent studies have shown that the third gradient furthermore 
1 place in the MDN (Turnbull et al., 2020; Turnbull et al., 2019a). The MDN, including fronto2 parietal and dorsal attention networks, has been implicated in attention/executive function 3 (Alcala-Lopez et al., 2018; Assem et al., 2020). Indeed, whereas task-based activations in 4 perspective-taking showed overlap with the DMN, task-based activation associated with 5 attention related to MDN. Conversely, socio-affective skills were found to be in the middle of 6 the organizational axis dissociating MDN from DMN. This positioning of socio-affective 7 task-based activations along the third gradient between attention and ToM may be reflective 8 of a regulative role of functional activity of MDN and DMN (Menon and Uddin, 2010). As 9 such, we could show that the task-based functional activations associated with attention, socio-affect and socio-cognition each were placed at unique locations along cardinal axes of functional organization, particularly those dissociating MDN from DMN and other cortical networks.

Studying functional network plasticity following ReSource training, we found that regions in both the MDN and DMN integrated further following Perspective training, whereas they segregated following Presence. In the context of social cognition, integrated states might reflect active thought processes such as those required when engaging in ToM, while more segregated states may reflect automation and domain-specific function (Finc et al., 2020). Mindfulness cultivated during Presence may reduce habitual thought patterns and enhance momentary awareness (Lutz et al., 2019) - possibly captured by functional network segregation. Corroborating these findings, Presence training shifted the socio-cognitive network along the principal gradient G1, indicating a segregation of this network from more perceptual/action driven modes of processing. Our observations in the domain of social skill training align with previous mental training studies in other domains; working memory task performance has been associated with decreased modularity (increased integration) whereas automation following working memory training was associated with increased modularity (segregation) of MDN and DMN (Finc et al., 2020). Second, mental training has been reported to result in reduced intra-network connectivity in the DMN, VAN and somatomotor networks, reflecting integration (Cotier et al., 2017). More generally, our findings may be in line with the Global Workspace Theory, which poses that automated tasks can be performed within segregated clusters of regions, whereas those that are novel and challenging require integration (Dehaene et al., 1998). Importantly, previous literature has indicated that functional brain networks are dominated by stable group and individual factors (Gratton et al., 2018). At the same time, functional activity is inherently dynamic, reflecting different cognitive states associated with faciliatory and inhibitory processing (Shine et al., 2018; Shine and Poldrack, 2018). Thus, it is likely that though each functional network has its place within large-scale functional organization, changes enabled by mental training reflect more dynamic elements of functional network organization. As such, our work expands pervious findings on region-specific effects (Tang et al., 2015) by providing a system-level perspective on how the social brain adaptively reconfigures following targeted, and multifaceted interventions.

41 We did not observe changes in eccentricity of task-based networks following the Affect 42 training module. However, core nodes of the VAN, also referred to as saliency network 43 (Uddin, 2015), such as the supramarginal gyrus and insula, shifted upwards along the 
1 principal gradient G1, indicating that this network may more closely affiliate with the MDN 2 and the DMN following this module. The VAN has been implicated in empathy (Lamm et al., 3 2011; Turnbull et al., 2019b), and may also contribute to the regulation of high-level 4 cognitive processes and attention. Previous work has furthermore suggested VAN are part of 5 the diverse club, a set of regions with high participation coefficients reflecting their diverse 6 connectivity patterns supporting global integration (Bertolero et al., 2017). Its change may 7 reflect a processing shift of the VAN towards a more integrative functional role. In addition, 8 these regions are suggested to mediate the activity within fronto-parietal and DMN (Menon, 9 2015; Menon and Uddin, 2010). It is possible that the lack of change in eccentricity and increases of the VAN along G1 following socio-affective training reflects such a coordinating role (whereas its decreases following mindfulness attention result in lack of coordination and increased segregation). Such an interpretation aligns with theories of emotional allostasis, suggesting that affective processing may balance integration and segregation of brain function to regulate resources dynamically (Barrett, 2017; Chun et al., 2011). Notably, though the current work focused on cortical networks, it is likely also subcortical regions contribute to the functional organization of the social brain (Kanske et al., 2015; Shine, 2020). Follow-up work that studies plasticity of sub-cortical function and structure in the context of the social brain will provide additional system-level insights on the social brain.

Using supervised learning with cross-validation, we found behavioral markers of social functions to be associated with training-related reorganization in functional connectome axes. In particular, we could predict both compassion and perspective-taking change during the Affect and Perspective blocks. Affect training nurtured compassion, prosocial motivation, and emotional regulation, as reflected in the increases in compassion scores following the Affect module in particular. We observed that increased weights in temporal/limbic regions following Affect could predict compassion change. Previous work suggests compassion/positive affect is likely emotion-motivational systems (Klimecki et al., 2014) but also interoceptive information (Barrett, 2017), as supported by (para)limbic regions such as ventral anterior insula and parahippocampa regions (Barrett, 2017; Turnbull et al., 2020; Turnbull et al., 2019b). On the other hand, Perspective training focused on training perspective-taking of self and others and was associated with increases in ToM scores (Trautwein et al., 2020). Behavioral change in perspective-taking following Perspective could be predicted by positive weights in the DMN (which overlaps with the task-based ToM network), whereas the MDN (which overlaps with the task-based attention network) had decreased weights. This may reflect that increases in perspective-taking are supported by a dissociation of focussed, externally-oriented processes mediated by MDN function and DMN functions that increasingly integrate these with internally-oriented processing (Turnbull et al., 2020). These observations underscore the differentiation between socio-emotional and sociocognitive processes, and provide evidence that change in compassion and perspective-taking is captured by change intrinsic functional reorganization at the level of the individual.

40 In sum, by combining cross-sectional with longitudinal approaches, we could show how 41 different modules of social mental training resulted in changes in functional network 42 organization. In line with prior work on the relationship between grey matter structure and the 43 ReSource training in the same sample (Valk et al., 2017), our work shows intrinsic 
Valk et al. | Changing the social brain

1 separability of processes underlying social functions. Notably, our work, in part, relied on

2 within-sample task-based activations associated with attention, socio-affective, and socio-

3 cognitive domains and previous work indicates that functional activations in tasks probing

4 social processes are variable as a function of task operationalization (Schurz et al., 2020a;

5 Schurz et al., 2014; Schurz et al., 2020b). Indeed, though meta-analytical decoding showed all

6 three tasks were associated with the probed functions based on the task-based neuroimaging

7 literature, they additionally involved other processes such as inhibition, cognitive control and

8 memory (Alcala-Lopez et al., 2019; Schurz et al., 2020a; Schurz et al., 2014; Schurz et al.,

9 2020b). Moreover, task-based activations used in the current study could be associated with

10 different transcriptomic patterns, replicating and expanding prior work linking task-based

11 activations with transcriptomic organization (Hansen et al., 2021), suggesting they may reflect

12 differentiable neurogenetic pathways. Taken together, the current work underscores the

13 differentiation of processes underlying our ability of understand the thoughts and feelings of

14 ourselves and others within the functional organization of the human brain, providing a

15 system-level perspective on social functioning. 
bioRxiv preprint doi: https://doi.org/10.1101/2020.11.11.377895; this version posted June 7, 2021. The copyright holder for this preprint (which

was not certified by peer review) is the author/funder, who has granted bioRxiv a license to display the preprint in perpetuity. It is made

Valk et al. | Changing the social brain

\section{MATERIALS AND METHODS}

\section{Experimental design}

3 Participants. A total of 332 healthy adults (197 women, mean $\pm \mathrm{SD}=40.7 \pm 9.2$ years, 20-55

4 years), recruited in 2012-2014 participated in the study, see Table 1 for more details. More

5 than $95 \%$ of our sample was Caucasian, with catchment areas balanced across two German

6 municipalities (Berlin and Leipzig). Participant eligibility was determined through a multi-

7 stage procedure that involved several screening and mental health questionnaires, together

8 with a phone interview [for details, see (Singer et al., 2016)]. Next, a face-to-face mental

9 health diagnostic interview with a trained clinical psychologist was scheduled. The interview

10 included a computer-assisted German version of the Structured Clinical Interview for DSM-

11 IV Axis-I disorders, SCID-I DIA-X (Wittchen and Pfister, 1997) and a personal interview,

12 SCID-II, for Axis-II disorders (First et al., 1997; Wittchen et al., 1997). Participants were

13 excluded if they fulfilled criteria for: i) an Axis-I disorder within the past two years; ii)

14 Schizophrenia, psychotic disorders, bipolar disorder, substance dependency, or an Axis-II

15 disorder at any time in their life. No participant had a history of neurological disorders or

16 head trauma, based on an in-house self-report questionnaire used to screen all volunteers prior

17 to imaging investigations. In addition, participants underwent a diagnostic radiological

18 evaluation to rule out the presence of mass lesions (e.g., tumors, vascular malformations). All

19 participants gave written informed consent and the study was approved by the Research

20 Ethics Committees of the University of Leipzig (\#376/12-ff) and Humboldt University in

21 Berlin (\#2013-02, 2013-29, 2014-10). The study was registered at ClinicalTrials.gov under

22 the title "Plasticity of the Compassionate Brain" (\#NCT01833104). For details on recruitment

23 and sample selection, see the full cohort and study descriptor (Singer et al., 2016).

Study design. Our study focused on two training groups: training cohort 1 (TC1, n=80 at enrolment) and training cohort 2 (TC2, $\mathrm{n}=81$ at enrolment), as well as a retest control cohort (RCC) that was partly measured prior to ( $\mathrm{n}=30$ at enrolment) and partly after ( $\mathrm{n}=60$ at enrolment) TC1 and TC2. A third training cohort (TC3, n=81 at enrolment) underwent an independent training program, and was included as an additional active control for the Presence module. Participants were selected from a larger pool of potential volunteers by bootstrapping without replacement, creating cohorts not differing significantly with respect to several demographic and self-report traits. Total training duration of TC1 and TC2 was 39 weeks ( nine months), divided into three modules: Presence, Affect, and Perspective (see below, for details), each lasting for 13 weeks (Figure 1). TC3 only participated in one 13week Affect training, and is only included in supplementary robustness analyses, so that the main analysis of functional plasticity focusses on TC1 and TC2. Our main cohorts of interest, TC1 and TC2, underwent Affect and Perspective modules in different order to act as active control cohorts for each other. Specifically, TC1 underwent "Presence-Affect-Perspective", whereas TC2 underwent "Presence-Perspective-Affect". TC1, TC2, and RCC underwent four testing phases. The baseline-testing phase is called T0; testing phases at the end of the xth module are called Tx (i.e., T1, T2, T3). In RCC, testing was carried out at similarly spaced intervals. The study had a slightly time-shifted design, where different groups started at different time points to simultaneously accommodate scanner and teacher availability. As we focused on training-related effects, we did not include analysis of a follow-up measurement 
bioRxiv preprint doi: https://doi.org/10.1101/2020.11.11.377895; this version posted June 7, 2021. The copyright holder for this preprint (which

was not certified by peer review) is the author/funder, who has granted bioRxiv a license to display the preprint in perpetuity. It is made available under aCC-BY-NC-ND 4.0 International license.

Valk et al. | Changing the social brain

1 T4 that was carried out 4, 5, or 10 months after the official training had ended. For details on

2 training and practice set-up, timeline, and measures, see (Singer et al., 2016).

3 Final sample. We excluded individuals with missing structural and/or functional MRI data 4 and/or a framewise-displacement of $>0.3 \mathrm{~mm}(<5 \%)$ (Power et al., 2012) and individuals with 5 gradients that showed less than $\mathrm{r}=0.5$ correspondence to the average gradient patterns were 6 disregarded for analysis $(<1 \%)$, as recommended (Hong et al., 2020). Further details of 7 sample size per time-point and exclusion criteria are in Table 1-3.

8 Table 1. Participant inclusion in resting-state analysis.

9

10

11

12

13

14

15

16

17

18

19

\begin{tabular}{|c|c|c|c|c|}
\hline Recruited (N, mean age, \% female) & $\mathrm{T}_{0}(\mathrm{~N})$ & $\mathrm{T}_{1}(\mathrm{~N})$ & $\mathrm{T}_{2}(\mathrm{~N})$ & $\mathrm{T}_{3}(\mathrm{~N})$ \\
\hline Total $(\mathrm{N}=332)$ & 284 & 264 & 185 & 188 \\
TC1 $(\mathrm{N}=80 ; 41.3 ; 58.8)$ & 72 & 66 & 56 & 55 \\
TC2 $(\mathrm{N}=81 ; 41.2 ; 59.3)$ & 69 & 60 & 63 & 67 \\
RCC $(\mathrm{N}=90 ; 40.0 ; 58.9)$ & 72 & 71 & 66 & \\
TC3 $(\mathrm{N}=81 ; 40.4 ; 60.5)$ & 71 & 67 & & \\
& & & & \\
\hline
\end{tabular}

Table 2. Reason for missing data across the study duration. $M R$ incidental findings are based on $\mathrm{T}_{0}$ radiological evaluations; participants who did not survive MRI quality control refers to movement and/or artefacts in the T1-weighted MRI; dropout details can be found in (Singer et al., 2016); no MRT: due to illness / scheduling issues / discomfort in scanner; other: non-disclosed; functional MRI missing: no complete functional MRI; functional MRI quality: $>0.3 \mathrm{~mm}$ movement (low quality in volume + surface)

\begin{tabular}{|l|l|l|l|l|}
\hline $\begin{array}{l}\text { Reason for dropout } \\
\text { (TC1, TC2, RCC) }\end{array}$ & $\mathrm{T}_{0}$ & $\mathrm{~T}_{1}$ & $\mathrm{~T}_{2}$ & $\mathrm{~T}_{3}$ \\
\hline & & & & \\
Structural MR incidental finding & 5 & $\left(5\right.$ based on $\left.\mathrm{T}_{0}\right)$ & $\left(5\right.$ based on $\left.\mathrm{T}_{0}\right)$ & $\left(5\right.$ based on $\left.\mathrm{T}_{0}\right)$ \\
Structural MRI quality control & 7 & 6 & 4 & 2 \\
Dropout & 2 & $7\left(2\right.$ based on $\left.\mathrm{T}_{0}\right)$ & $7\left(9\right.$ based on $\left.\mathrm{T}_{01}\right)$ & $7\left(16\right.$ based on $\left.\mathrm{T}_{012}\right)$ \\
Medical reasons & 1 & $7\left(1\right.$ based on $\left.\mathrm{T}_{0}\right)$ & $7\left(8\right.$ based on $\left.\mathrm{T}_{01}\right)$ & $\left(15\right.$ based on $\left.\mathrm{T}_{012}\right)$ \\
Other & 4 & 10 & 7 & 7 \\
Functional MRI missing & 4 & 10 & 11 & 4 \\
Functional MRI quality & $14(26)$ & $5(23)$ & $8(14)$ & $3(5)$ \\
\hline
\end{tabular}

Table 3. Reason for missing data across the study duration. $M R$ incidental findings are based on $\mathrm{T}_{0}$ radiological evaluations; participants who did not survive MRI quality control refers to movement and/or artefacts in the T1-weighted MRI; dropout details can be found in (Singer et al., 2016); no MRT: due to illness / scheduling issues / discomfort in scanner; other: non-disclosed.

\begin{tabular}{|c|c|c|}
\hline & $\mathrm{T}_{0}$ & $\mathrm{~T}_{1}$ \\
\hline Reason for dropout (TC3) & 3 & (3 based on $\left.\mathrm{T}_{0}\right)$ \\
MR incidental finding & 0 & 0 \\
MRI quality control & 0 & 3 \\
Dropout & 1 & 2 \\
Medical reasons & 5 & 3 \\
Other & 2 & 0 \\
Functional MRI missing & $1(1)$ & $3(4)$ \\
Functional MRI quality & & \\
\hline
\end{tabular}


bioRxiv preprint doi: https://doi.org/10.1101/2020.11.11.377895; this version posted June 7, 2021. The copyright holder for this preprint (which

was not certified by peer review) is the author/funder, who has granted bioRxiv a license to display the preprint in perpetuity. It is made available under aCC-BY-NC-ND 4.0 International license.

Valk et al. | Changing the social brain

Neuroimaging acquisition and analysis

MRI acquisition. MRI data were acquired on a 3T Siemens Magnetom Verio (Siemens Healthcare, Erlangen, Germany) using a 32-channel head coil. We recorded task-free functional MRI using a T2*-weighted gradient 2D-EPI sequence (repetition time $[\mathrm{TR}]=2000 \mathrm{~ms}$, echo time $[\mathrm{TE}]=27 \mathrm{~ms}$, flip angle $=90^{\circ} ; 37$ slices tilted at approximately $30^{\circ}$ with $3 \mathrm{~mm}$ slice thickness, field of view $[\mathrm{FOV}]=210 \times 210 \mathrm{~mm} 2$, matrix $=70 \times 70,3 \times 3 \times 3 \mathrm{~mm} 3$ voxels, $1 \mathrm{~mm}$ gap; 210 volumes per session). We also acquired a T1-weighted 3D-MPRAGE sequence $(176$ sagittal slices, $\mathrm{TR}=2300 \mathrm{~ms}, \mathrm{TE}=2.98 \mathrm{~ms}$, inversion time $[\mathrm{TI}]=900 \mathrm{~ms}$, flip angle $=7^{\circ}, F O V=240 \times 256 \mathrm{~mm}^{2}$, matrix $=240 \times 256,1 \times 1 \times 1 \mathrm{~mm}^{3}$ voxels). Throughout the duration of our longitudinal study, imaging hardware and console software (Syngo B17) were held constant. Participants also underwent multiple functional tasks, which had a variable number of volumes due to the different lengths of the tasks, but otherwise identical sequence parameters analogous to the task-free data (Kanske et al., 2015; Trautwein et al., 2016). During the functional session, participants were instructed to lie still in the scanner, think of nothing in particular, and fixate a white cross in the center of a black screen.

Task-free functional MRI analysis. Processing was based on DPARSF/REST for Matlab [http://www.restfmri.net (Song et al., 2011)]. We discarded the first 5 volumes to ensure steady-state magnetization, performed slice-time correction, motion correction and realignment, and co-registered functional time series of a given subject to the corresponding T1-weighted MRI. Images underwent unified segmentation and registration to MNI152, followed by nuisance covariate regression to remove effects of average WM and CSF signal, as well as 6 motion parameters ( 3 translations, 3 rotations). We included a scrubbing (Power et al., 2012) that modelled time points with a frame-wise displacement of $\geq 0.5 \mathrm{~mm}$, together with the preceding and subsequent time points as separate regressors during nuisance covariate correction. Volume-based timeseries were mapped to the fsaverage5 surface using bbregister.

Gradient construction. In line with previous studies evaluating functional gradients (Bethlehem et al., 2020; Hong et al., 2019; Margulies et al., 2016; Paquola et al., 2019; Vos de Wael et al., 2020; Vos de Wael et al., 2018) the functional connectivity matrix was proportionally thresholded at $90 \%$ per row and converted into a normalised angle matrix using the BrainSpace toolbox for MATLAB (Vos de Wael et al., 2020). Diffusion map embedding, a nonlinear manifold learning technique (Coifman et al., 2005), identified principal gradient components, explaining functional connectivity variance in descending order. In brief, the algorithm estimates a low-dimensional embedding from a highdimensional affinity matrix. In this space, cortical nodes that are strongly interconnected by either many suprathreshold edges or few very strong edges are closer together, whereas nodes with little or no functional connectivity are farther apart. The name of this approach, which belongs to the family of graph Laplacians, derives from the equivalence of the Euclidean distance between points in the embedded space and the diffusion distance between probability distributions centred at those points. It is controlled by the parameter $\alpha$, which controls the influence of the density of sampling points on the manifold ( $\alpha=0$, maximal influence; $\alpha=1$, no influence). Based on previous work (Margulies et al., 2016), we set $\alpha=0.5$, a choice that retains the global relations between data points in the embedded space and has been suggested to be relatively robust to noise in the functional connectivity matrix. The diffusion time (t), 
1 which controls the scale of eigenvalues of the diffusion operator was set at $t=0$ (default).

2 Individual embedding solutions were aligned to the group-level embedding based on the

3 Human Connectome Project S1200 sample (Van Essen et al., 2013) via Procrustes rotations

4 (Vos de Wael et al., 2020). The Procrustes alignment enables comparison across individual

5 embedding solutions, provided the original data is equivalent enough to produce comparable

6 Euclidean spaces.

$73 D$ gradient metric: eccentricity. To construct the combined gradient, we computed the

8 Euclidean distance to the individual center for gradient 1-3. Next, to evaluate change within

9 and between individuals, we computed the difference between gradient scores between

10 different time-points.

$113 D$ gradient metric: dispersion. To investigate multi-dimensional differences in cortical 12 organization, we quantified dispersion of task-based networks (Kanske et al., 2015; Trautwein 13 et al., 2016) and functional networks (Yeo et al., 2011) in 3D space. Each axis of this 3D 14 space was defined by the values along the first three gradients. Within network dispersion was 15 quantified as sum squared Euclidean distance of network nodes to the network centroid at 16 individual level. Between network dispersion was calculated as the Euclidean distance 17 between network centroids. These metrics were calculated for each subject within the 18 individualized, aligned gradient space similar to previous work (Bethlehem et al., 2020).

19 Graph theoretical metrics. To further validate our gradient-based metric of integration and 20 segregation, we also computed clustering coefficient and path length using the Brain 21 Connectivity Toolbox (Rubinov and Sporns, 2010). Both measures were computed in the 22 parcel-level, by averaging the individual connectomes within the 400 Schaefer parcels 23 (Schaefer et al., 2018) and with a threshold at the top 10\% of connections, analogue to our 24 gradient approach.

25 Task-based functional networks. Paradigms identifying functional localizers are previously described (Kanske et al., 2015; Trautwein et al., 2016). In short, the attention network was defined based on the conjunction of activation following selective attention and executive control during a cued-flanker task. The socio-affective network was based on the contrast between emotional and non-emotional videos and the socio-cognitive network was based on the contrast between ToM and non-ToM questions. Networks were mapped to the fsaverage 5 surface-template to evaluate their embedding within the intrinsic gradient space constructed from the resting-state fMRI data.

\section{Behavioral markers}

34 We assessed a battery of behavioral markers developed and adapted to target the main aims of 35 the Presence, Perspective, and Affect modules: selective attention, compassion, and ToM. 36 Behavioral changes of these markers elicited by the different modules are reported elsewhere 37 (Trautwein et al., 2020). The measure for compassion was based on the EmpaToM task, a 38 developed and validated naturalistic video paradigm in the current subjects (Kanske et al., 39 2015; Tholen et al., 2020). Videos showed people recounting autobiographical episodes that 40 were either emotionally negative (e.g., loss of a loved one) or neutral (e.g., commuting to 41 work), followed by Likert-scale ratings of experienced valence and compassion. Since the 42 conceptual understanding of compassion might change due to the training, we ensured a 
1 consistent understanding by defining it prior to each measurement as experiencing feelings of 2 care, warmth, and benevolence. Compassion was quantified as mean of compassion ratings 3 across all experimental conditions. The EmpaToM task (Kanske et al., 2015) also allowed for 4 measurement of ToM performance. After the ratings, multiple-choice questions requiring 5 inference of mental states (thoughts, intentions, beliefs) of the person in the video or factual 6 reasoning on the video's content (control condition) were asked. Questions had three response 7 options and only one correct answer, which had been validated during pre-study piloting 8 (Kanske et al., 2015). Here, we calculated participants' error rates during the ToM questions 9 after the video, collapsed across neutral and negative conditions.

\section{$10 \quad$ Statistical analysis}

11 Analysis was performed using SurfStat for Matlab (Worsley et al., 2009). We employed linear mixed-effects models, a flexible statistical technique that allows for inclusion of multiple measurements per subjects and irregular measurement intervals (Pinheiro and Bates, 2000). In all models, we controlled for age and sex, and random effect of subject. Inference was performed on subject-specific eccentricity/gradient change maps, $\Delta$ eccentricity/gradient, which were generated by subtracting vertex-wise eccentricity/gradient maps of subsequent time points for a given participant.

a) Assessing module-specific change. To compare the modules against each other, we contrasted change of one given module against the average of the other two modules. To compare two modules, we compared one training module against another (for example Affect versus Perspective). To compare a given module against RCC, we estimated contrasts for training cohort change relative to RCC (Presence, Perspective, Affect).

b) Correction for multiple comparisons. Whole brain findings were corrected for multiple comparisons using random field theory for non-isotropic images (Worsley et al., 1999) with cluster-forming thresholds of $\mathrm{p}=0.005$, two-tailed. Post-hoc network-based assessments were corrected for number of tests within the analysis step using FDR correction (Benjamini and Hochberg, 1995). Post-hoc whole cortex eccentricity/gradient change in TC1 and TC2 separately were thresholded with cluster-forming threshold at $\mathrm{p}=0.01$, two-tailed.

c) Global signal regression. To assess the effects of global signal on our main longitudinal results we created connectivity matrixes while regressing out global signal within a 400 parcel solution (Schaefer et al., 2018) and captured change within task-based networks.

Theoretically, the cross-over design of the study and the inclusion of number of scans since baseline as covariance controlled for test-retest effects on motion (as participants may become calmer in scanner after repeated sessions). Nevertheless, to control for outliers, we removed all individuals with $>0.3 \mathrm{~mm} /$ degree movement (Power et al., 2012).

\section{Behavioral prediction}

We adopted a supervised machine learning framework with cross-validation to predict behavioral change based on change in functional connectivity organization. We aimed at predicting attention, compassion, and perspective-taking (Figure 4). We regressed out age and sex, and computed a binned change score to account for outliers. We utilized 5-fold cross-validation separating training and test data. Feature selection procedure was conducted 
1 training data. Based on our vertex wise manifold summary, a set of features that could predict 2 each behavioral score was identified using Lasso regularization, i.e. an L1 penalization on the 3 parameters. Linear regression for predicting behavioral scores was constructed using the 4 selected features as independent variables within the training data (4/5 segments) and it was 5 applied to the test data (1/5 segment) to predict their behavioral scores. Prediction procedure 6 was repeated 5000 times with different set of training and test data to avoid bias for separating 7 subjects. The prediction accuracy was assessed by calculating Pearson's correlation between 8 the actual and predicted behavioral scores as well as their mean absolute error, MAE (Chang 9 et al., 2015).

Meta-analytical decoding We used the NeuroSynth meta-analytic database (http://www.neurosynth.org) (Yarkoni et al., 2011) to assess topic terms associated with social, affective, interoceptive, and cognitive functioning. ("affect", "autonomic", "emotion", "emotion regulation”, "empathy”, "episodic memory”, "goal directed”, "interoceptive”, "mentalizing”, "reward”, "self”, "semantic memory", "social", "social interaction", "theory mind", "inhibition", "executive", "cognitive control", "attention", "working memory”). We used a t-test to compare there was significantly activation associated with a certain term relative to the activity outside the task-based activation. Following, after correcting for number of contrasts tested, we plotted the functions significantly associated with the respective task-based activation.

Transcriptomic association analysis

To provide additional neurobiological context of our findings, we assessed spatial correlations of task-based functional activations in attention and socio-affective, and socio-cognitive processing and gene expression patterns. Initially, we correlated the t-statistics map of the functional activations and the post-mortem gene expression maps provided by Allen Institute for Brain Sciences (AIBS) using the Neurovault gene decoding tool (Gorgolewski et al., 2014; Hawrylycz et al., 2012). Neurovault implements mixed-effect analysis to estimate associations between the input t-statistic map and the genes of AIBS donor brains yielding the gene symbols associated with the input t-statistic map. Gene symbols that passed a significance level of FDR-corrected $p<0.05$ and showed a positive association with the taskbased were further tested whether they are consistently expressed across the donors using abagen toolbox (https://github.com/rmarkello/abagen)(Arnatkeviciute et al., 2019). For each gene, we estimated whole-brain gene expression map and correlated it between all pair of different donors. Genes showing consistent whole-brain expression pattern across donors $(r>0.5)$. In a second stage, gene lists that were significant were fed into enrichment analysis, which involved comparison against developmental expression profiles from the BrainSpan dataset (http://www.brainspan.org) using the cell-type specific expression analysis (CSEA) developmental expression tool (http://genetics.wustl.edu/jdlab/csea- tool-2) (Dougherty et al., 2010). As the AIBS repository is composed of adult post-mortem datasets, it should be noted that the associated gene symbols represent indirect associations with the input t-statistic map derived from the developmental data. 
bioRxiv preprint doi: https://doi.org/10.1101/2020.11.11.377895; this version posted June 7, 2021. The copyright holder for this preprint (which was not certified by peer review) is the author/funder, who has granted bioRxiv a license to display the preprint in perpetuity. It is made available under aCC-BY-NC-ND 4.0 International license.

Valk et al. | Changing the social brain 
Valk et al. | Changing the social brain

\section{ACKNOWLEDGEMENTS}

2 Data for the ReSource project were collected between 2013 and 2016 at the Department of

3 Social Neuroscience at the Max Planck Institute for Human Cognitive and Brain Sciences

4 Leipzig. Tania Singer (Principal Investigator) received funding for the ReSource Project from

5 the European Research Council (ERC) under the European Community's Seventh Framework

6 Program (FP7/2007-2013) ERC grant agreement number 205557. Sofie Valk received

7 support from the Max Planck Society (Otto Hahn Award). Boris Bernhardt acknowledges

8 research support from the NSERC (Discovery-1304413), the Canadian Institutes of Health

9 Research (CIHR FDN-154298), SickKids Foundation (NI17-039), Azrieli Center for Autism

10 Research (ACAR-TACC), and the Tier-2 Canada Research Chairs program. Bo-yong Park

11 was funded by Molson Neuro-Engineering fellowship by Montreal Neurological Institute and

12 Hospital (MNI) and the Fonds de la Recherche du Quebec - Santé. We thank Lisa Feldman

13 Barrett for fruitful discussions during the conception of this manuscript. Data and materials

14 availability: All data needed to evaluate the conclusions in the paper are present in the paper

15 and/or the Supplementary Materials. Scripts and code are available at

16 https://github.com/CNG-LAB/cngopen/tree/main/social gradients. Author

17 contributions: SLV and BCB were involved in data acquisition and processing, and

18 conceived and designed the resting-state computational experiments. SH and BP contributed

19 to development of gradient and genetic enrichment analysis. F.-M.T., A.B., and P.K. designed

20 and analyzed the functional and behavioral data used in this study. T.S. initiated and

21 developed the ReSource Project and model, as well as the training protocol. All authors

22 discussed, wrote, and approved the final version of the manuscript. Competing interests: The

23 authors declare that they have no competing interests. 
Valk et al. | Changing the social brain

\title{
1 CHANGING THE SOCIAL BRAIN: PLASTICITY ALONG MACRO-SCALE AXES OF
}

\section{SUPPLEMENT}

Sofie L Valk ${ }^{1,2 \Delta}$; Philipp Kanske ${ }^{3,4}$; Bo-yong Park ${ }^{5}$; Seok-Jun Hong ${ }^{6-8}$; Anne BöcklerRaettig $^{9}$; Fynn-Mathis Trautwein ${ }^{10}$; Boris C. Bernhardt ${ }^{5 *}$, Tania Singer ${ }^{11} *$

\author{
* joint co-authors
}

1. Otto Hahn Group Cognitive Neurogenetics, Max Planck Institute for Human Cognitive and Brain Sciences, Leipzig, Germany; 2. INM-7, FZ Jülich, Jülich, Germany; 3. Clinical Psychology and Behavioral Neuroscience, Faculty of Psychology, Technische Universität Dresden, Dresden, Germany; 4. Max Planck Institute for Human Cognitive and Brain Sciences, Leipzig, Germany; 5. Multimodal Imaging and Connectome Analysis Lab, McConnell Brain Imaging Centre, Montreal Neurological Institute and Hospital, McGill University, Montreal, Quebec, Canada; 6. Center for the Developing Brain, Child Mind Institute, NY, USA; 7. Center for Neuroscience Imaging Research, Institute for Basic Science, Suwon, South Korea; 8. Department of Biomedical Engineering, Sungkyunkwan University, Suwon, South Korea; 9. Department of Psychology, Leibniz University Hannover, Germany; 10. Klinik für Psychosomatische Medizin und Psychotherapie, Universitäts Klinikum Freiburg, Freiburg, Germany; 11. Social Neuroscience Lab, Max Planck Society, Berlin, Germany 
Valk et al. | Changing the social brain

\section{SuPPlementary Materials AND Methods}

\section{$2 \quad$ Training modules}

3 Each module started off with a three-day intensive retreat, followed by weekly group sessions 4 with the teachers and daily home practice supported by a custom-made internet platform and smartphone applications providing: i) audio streams for guided meditations and ii) an interface for dyadic exercises (Figure 1) (Singer et al., 2016). During the retreat, participants were introduced to topics and associated core exercises of the upcoming module. Training during the subsequent eight weeks included weekly two-hour-long sessions with instructors that included discussion of training challenges and effects, practice of the core exercises, and introduction to new contemplative practices. The last five weeks of each module were used to consolidate previous topics, with no new topics being introduced. Presence modules were always first in order to stabilize the mind and prepare the participants for the socio-cognitive and socio-affective training modules.

Presence: Core exercises, practiced repeatedly during the retreat, in the weekly sessions, and at home (instruction was to practice at least five times per week), were Breathing Meditation and Body Scan (Kabat-Zinn, 1990). The instruction for the Breathing Meditation was to focus attention on sensations of breathing and to refocus attention whenever it drifted. The Body Scan involved focusing on various parts of the body in a systematic fashion (e.g., from toes to head), while paying close attention to perceptions occurring in these body parts. Additional exercises of Presence, also practiced during the retreat and weekly sessions, were walking meditation, meditations on vision, sound, and taste, as well as an open presence meditation. These practices require a deliberate focus of attention on certain facets of present moment-tomoment experience, monitoring of distractions, and reorienting towards the object of attention in the meditation, be it the breath, a sound or a visual object.

Affect: Core exercises were Loving-kindness Meditation (Salzberg, 1995) and the 'Affect Dyad' (Kok and Singer, 2016; Singer et al., 2016). For Loving-kindness Meditation, participants were first familiarised to ways of connecting with the feeling and motivation of love and care, such as imagining a baby, a cute animal, a close benevolent other, a place of safety and comfort, or focusing on sensations of warmth in the body. These feelings can then be directed towards oneself and others. The typical instruction for the Loving-kindness Meditation was to start with imagining oneself and then a benefactor, where such feelings might arise naturally, and then to extend feelings of Loving-kindness and good wishes to self and then the benefactor. Over the course of several sessions, participants were asked to successively extent these feelings to others to whom one feels neutral, people one has difficulties with, and ultimately all humans and sentient beings. To foster experiences of Loving-kindness, participants were instructed to mentally repeat phrases such as "May you be happy", "May you be healthy", "May you be safe", and "May you live with ease".

38 The Affect Dyad is a partner practise done face-to-face during the retreat, during the weekly 39 sessions, and via the web- or smartphone-based application during daily practice at home. 40 During this exercise, participants contemplated situations from their last day that they 41 experienced as difficult and situations which they were grateful for. Partner A was instructed 42 to listen attentively to what the speaker (partner B) has to say without giving verbal or non- 
1 verbal feedback, promoting empathic listening. The speaker remembered the situation and 2 how it felt like and focused on the immediate subjective affective and bodily experience 3 without engaging in abstract reasoning or interpretation. After a first run, roles were switched. 4 This contemplative dialogue allows cultivating empathic listening in the listener and 5 observing difficult emotions and their effect on the body as well as developing gratitude and 6 positive affect in the speaker. Additional features of Affect were exploration of emotions in an 7 attitude of acceptance and care, a guided mental training that contrasts empathy and 8 compassion and teaches participants how to transform an empathic into a loving and 9 compassionate response when confronted with the suffering of others (Klimecki et al., 2014), forgiveness meditation, and development of self-compassion (Neff and Germer, 2013).

Perspective: Core exercises were an Observing-thoughts Meditation and a 'Perspective Dyad'. In the former, the objective was to observe thoughts as mental events or natural phenomena and not as direct representations of reality. In the starting phase of the practice, this was supported by identifying thoughts using opposite poles such as me/other, past/future, positive/negative, or more generic labels such as "judging" and "thinking". Later in the program, participants were instructed to observe the coming and going of thoughts without getting involved in them.

The Perspective Dyad is a partner exercise with a structure comparable to the Affect Dyad. This exercise was partly based on the Internal Family System approach by Schwartz and colleagues (Holmes, 2007; Schwarz, 1997) and on theoretical accounts distinguishing between affective (e.g., compassion and empathy) and cognitive (e.g., Theory of Mind, ToM) routes of social cognition (Singer, 2006, 2012). For this training of perspective-taking on self and others, participants were first introduced to the concept of inner parts, personality-traitlike patterns of cognition, emotion, and behavioral tendencies that dominate in certain situations and shape experience as well as behavior (Holmes, 2007). During the retreat and throughout the course, participants were supported in detecting inner parts. In the Perspective Dyad, the speaker described a situation of the last day from the perspective of one of his/her inner parts, that is, how the experience might have been if a certain inner part had been dominant. The other participant listened attentively without giving verbal or non-verbal feedback and tried to find out from which inner part the speaker was recounting the situation. The listener, thus, had to engage in cognitive perspective-taking on the other to find out "who is speaking" and to infer the needs, desires, and beliefs of the other. The speaker, in turn, needed to take a meta-perspective onto its own self-related aspects and to decouple from a lived and experienced reality. Additional elements of Perspective were exercises in which participants needed to take the perspective of people they encountered whom they have difficulties with in their daily lives, reflections on the central role that thoughts play in our lives, how these might differ for thoughts of others, and why understanding them differs from approving their behavior. This description of the training protocol was adapted from previous work (Singer et al., 2016; Valk et al., 2017). 
Valk et al. | Changing the social brain

\section{SUPPLEMENTARY RESULTS}

2 Task-based activation patterns in attention, socio-affect, and socio-cognitive function.

3 Assessing task-based activation patterns in attention, socio-affect, and socio-cognition.

4 (Figure 1), we observed task-specific and task-general activations between attention and

5 social functioning. Attention processing (i.e., the overlap between stimulus driven reorienting

6 and executive control in the cued-flanker task) was associated with functional activations in

7 bilateral inferior parietal and superior frontal regions. On the other hand, socio-affective

8 processing (i.e., the contrast of viewing emotional and neutral videos in the EmpaTom task),

9 implicated bilateral supramarginal, dorsolateral prefrontal and bilateral inferior frontal

10 regions. ToM (i.e., the contrast of ToM versus no-ToM questions in the EmpaToM) related to

11 activations in bilateral temporal and temporo-parietal, as well as medial prefrontal regions.

12 Attention and socio-affective processing both implicated the bilateral anterior insula and

13 anterior midline regions, and socio-affective and socio-cognitive processing both related to

14 temporal parietal, midline parietal and prefrontal, as well as inferior frontal regions, although

15 the peaks of the activation pattern in these broader brain areas clearly differ for the socio-

16 affective and socio-cognitive domains (see also (Kanske et al., 2015)). Our findings are thus

17 in line with previous work and demonstrate differentiable, but overlapping networks for 18 attention, socio-emotional, and socio-cognitive activations (Schurz et al., 2020a).

19

\section{Leveraging eccentricity against graph theoretical measures}

To further validate our gradient-based model of eccentricity (segregation and integration) we also created metrics of regional integration and segregation using graph theoretical approaches (Figure S1). We found a positive correspondence between gradient-based eccentricity and graph theory-based clustering coefficient $(r=0.641, \mathrm{p}<0.001)$ and path length $(\mathrm{r}=0.510, \mathrm{p}<0.001)$. Evaluating network-specific alterations following mental training these measures, we found increases of clustering coefficient (attention network: $t=2.489, p=0.021$ ) and path length (socio-cognitive network: $\mathrm{t}=2.374, \mathrm{p}=0.027$ ) following Presence training and decreases in both measures (clustering coefficient: socio-cognitive network: $t=-2.629$, $\mathrm{p}=0.015$ and path length attention network: $\mathrm{t}=-2.43, \mathrm{p}=0.03$, socio-affective network: $\mathrm{t}=-$ 2.843, $\mathrm{p}=0.01$, socio-cognitive network: $\mathrm{t}=-3.335, \mathrm{p}=0.003$ ).

\section{Eccentricity change in each training cohort}

Evaluating the alterations in each training cohort separately we observed similar effects (Figure S2). Specifically, in TC1 we found increases in eccentricity of left TPJ following Presence and decreases following Perspective (FWEp<0.05). In addition, we found decreases following Perspective in right superior temporal and right temporal pole (FWEp<0.05). Studying the changes in task-based networks, we observed increases in eccentricity following Presence in socio-affective $(\mathrm{t}=2.54, \mathrm{p}=0.03)$ and socio-cognitive $(\mathrm{t}=3.14, \mathrm{p}=0.005)$ networks and decreases in eccentricity following Perspective in the socio-cognitive task-based network $(\mathrm{t}=-3.07, \mathrm{p}=0.006)$. For TC2, we found increases in eccentricity in right opercular and right inferior temporal/ occipital regions following Presence and decreases in right inferior temporal/occipital regions following Perspective (FWEp<0.05). 
Valk et al. | Changing the social brain

1 Evaluating change against retest controls, we observed a decrease of eccentricity following

2 Perspective in task-based socio-cognitive network $(\mathrm{t}=-2.10, \mathrm{p}=0.05)$ at uncorrected

3 thresholds. Last, evaluating change between two modules, we observed difference between

4 Presence and Perspective in task-based attention networks $(\mathrm{t}=2.54, \mathrm{p}=0.04)$ and socio-

5 cognitive networks $(\mathrm{t}=3.22, \mathrm{p}=0.005)$.

\section{$7 \quad$ Global signal corrected analyses}

8 Correcting the functional connectivity matrices for global signal (GSR) before computing 9 gradient and eccentricity measures gave similar results as without GSR (Figure S3).

10 Specifically, along G1 we found a difference between attention and socio-affect network ( $\mathrm{t}=-$ $115.228, \mathrm{p}<0.001)$ and between the attention and socio-cognitive network $(\mathrm{t}=-5.63, \mathrm{p}<0.001)$. 12 Along G2 we observed a difference between socio-affect and socio-cognitive network ( $\mathrm{t}=-$ 13 2.813, p=0.015). Along G3 we observed a difference between all networks; attention versus 14 socio-affect $(\mathrm{t}=-6.353, \mathrm{p}<0.001)$, attention versus socio-cognition $(\mathrm{t}=-9.283, \mathrm{p}<0.001)$, and 15 socio-affect and socio-cognition $(\mathrm{t}=-2.96, \mathrm{p}=0.01)$. Testing alterations following training, we 16 observed that eccentricity increases in attention task-based networks following Presence $17(\mathrm{t}=2.232, \mathrm{p}=0.04)$, and decreased in attention task-based network $(\mathrm{t}=-2.50, \mathrm{p}=0.015)$ following 18 Perspective. In individual gradients we found that, along G1, the attention network decreased 19 following Presence ( $\mathrm{t}=-2.157, \mathrm{p}=0.048)$. For $\mathrm{G} 2$, Presence resulted in a decrease of the socio20 cognitive network $(\mathrm{t}=-2.918, \mathrm{p}=0.006)$.

\section{Social connections with eccentricity of functional communities.}

Evaluating longitudinal change within large-scale functional communities (Yeo et al., 2011)

(Figure S4), we found that Presence training resulted in increased eccentricity of dorsal attention networks $(\mathrm{t}=3.67, \mathrm{p}=0.002)$ and ventral attention networks $(\mathrm{t}=2.81, \mathrm{p}=0.04)$. Conversely, Perspective training resulted in decreased embedding of dorsal attention networks $(\mathrm{t}=-3.13, \mathrm{p}=0.02)$ and ventral attention network $(\mathrm{t}=-2.76, \mathrm{p}=0.05)$. Studying change in the individual large-scale gradients (G1-G3), we observed increases in the ventral attention network following Affect $(\mathrm{t}=3.00, \mathrm{p}=0.02)$ along $\mathrm{G} 1$. Last we observed decrease of the visual network following Affect $(\mathrm{t}=-4.02, \mathrm{p}<0.001)$ along $\mathrm{G} 3$.

\section{Change in first three large-scale gradients in each training cohort}

Reiterating analysis of Figure 2 in each training cohort separately (Figure S5 and Figure S6), we observed decreases in G1 following Presence in right superior parietal cortex extending to supramarginal gyrus in TC1 (FWEp<0.05). Conversely, Affect resulted in increases in G1 in right superior parietal cortex extending to supramarginal gyrus in TC1. In TC2, we observed increases in bilateral mid/anterior insula following Affect (FWEp <0.05). In task-based networks, we found the socio-cognitive network showed increases following Perspective in TC1 $(\mathrm{t}=2.62, \mathrm{p}<0.03)$. Along G2, we observed whole cortex alterations in TC2

40 for Presence, with increases in right lateral frontal regions and decreases of socio-affect task41 based network ( $\mathrm{t}=-2.86, \mathrm{p}=0.02)$ following Affect in this cohort. Along G3 we found decreases 
Valk et al. | Changing the social brain

1 Evaluating changes along G1-G3 in different contrasts, we observed no change relative to 2 retest controls, but decreases in Affect relative to Presence in socio-cognitive networks ( $\mathrm{t}=$ $32.05, \mathrm{p}=0.05$ ) along G1 at uncorrected threshold. For G2 we also observed no change relative 4 to retest controls but increases in Presence relative to Perspective in socio-affective networks $5(\mathrm{t}=1.98, \mathrm{p}=0.05$, uncorrected $)$, Affect relative to Presence in attention networks $(\mathrm{t}=-2.20$, $6 \mathrm{p}=0.03$, uncorrected) and socio-affective networks ( $\mathrm{t}=-2.37, \mathrm{p}=0.02$ uncorrected). For G3 we 7 observed no change versus RCC or between groups.

Behavior change prediction

10 Attention was not predictable using a multi-gradient approach (raw: $r=-0.21, p=0.06$; bin: $r=-$ $110.04, \mathrm{p}>0.1)$. Compassion and perspective-taking were less predictable using raw scores 12 (compassion raw: $\mathrm{r}=0.19, \mathrm{p}=0.06, \mathrm{MAE}=0.504$; perspective-taking raw: $\mathrm{r}=0.20, \mathrm{p}=0.05$, 13 MAE=0.099), yet distribution of weight maps was similar (Figure S7).

\section{Functional decoding of localizer networks}

Decoding task-based activations using large-scale functional communities (Yeo et al., 2011) we found that task-based activations associated with attention were predominantly in dorsal and ventral attention networks and fronto-parietal networks (Figure S4). Conversely, taskbased activations associated with socio-affective processing related to frontal parietal networks as well as default mode network and ventral attention network. ToM-based activations were associated with default mode network, and ventral attention and somatosensory network.

To further decode the association between task-based activations of social processing in the current sample we took an ad-hoc a meta-analytic approach using meta-analytic maps of social, cognitive, affective, and attentional terms in the Neurosynth database (Figure S8). We found differential relationships between each of the functional localizers and meta-analytical maps (FDRq $<0.05)$. Task-based activation of attention was associated with inhibition, executive functioning, cognitive control, attention, and working memory. Conversely, taskbased activation of socio-affective functioning was associated with affect, goal-directed behavior, episodic memory, executive functioning, emotion, social-interaction, cognitive control, emotion regulation, inhibition, self, empathy, social, ToM, and mentalizing. Sociocognitive task-based activations related to episodic memory, semantic memory, emotion, emotion regulation, empathy, social interaction, self, mentalizing, social, and ToM - meta34 analytical maps.

\section{Genetic decoding of the social brain}

37 Having functionally decoded task-based activations associated with attention and social 38 processing, we sought further understand the factors that contribute to the dissociable 39 activation patterns of social functioning (Figure S9, Tables S1-3)

40 Specifically, we correlated the task-based activation during attention, socio-affective and 41 socio-cognitive tasks with post-mortem gene expression data from the Allen Institute of Brain 
Valk et al. | Changing the social brain

1 Sciences (AIBS) (Hawrylycz et al., 2012). Among significantly associated genes, we selected 2 only those consistently expressed ( $r>0.5$ ) among donors. We then used developmental gene 3 set enrichment analysis (Dougherty et al., 2010), to identify spatiotemporal time windows in 4 which these genes are most frequently expressed. The analysis suggested a differential 5 patterning between attention, socio-affective, and socio-cognitive processes. Activations 6 associated with reorienting and executive control of attention were predominantly in 7 cerebellum and thalamus during childhood and adolescence, and showed a positive increase 8 along development $(\mathrm{r}=0.797, \mathrm{p}=0.006)$, whereas socio-cognitive activations were associated 9 with striatal expression in adolescence and early adulthood, and did not show association with 10 development $(\mathrm{r}=-0.497, \mathrm{p}>0.1)$. Socio-affective activations were associated with both 11 thalamus in early fetal and adolescent time windows, as well as cerebellum across 12 development, and had a negative relationship with developmental expression $(\mathrm{r}=-0.86$, $13 \mathrm{p}=0.002$ ).

Network-based metrics of eccentricity change

16 In addition, we computed network-level index of segregation and integration; the dispersion 17 within as well as distance between task-based fMRI activations in 3D gradient space 18 (Bethlehem et al., 2020) (Supplementary Figure 10). Using these metrics to evaluate change 19 we found increased between network distance between attention and socio-affective $(\mathrm{t}=2.81$, $20 \mathrm{p}=0.03)$ and attention and socio-cognitive $(\mathrm{t}=2.46, \mathrm{p}=0.05)$ networks following Presence. 21 Conversely, Perspective resulted in a decrease in between network distance between attention 22 and socio-affective network $(\mathrm{t}=-2.42, \mathrm{p}=0.05)$. 
bioRxiv preprint doi: https://doi.org/10.1101/2020.11.11.377895; this version posted June 7, 2021. The copyright holder for this preprint (which was not certified by peer review) is the author/funder, who has granted bioRxiv a license to display the preprint in perpetuity. It is made available under aCC-BY-NC-ND 4.0 International license.

Valk et al. | Changing the social brain

\section{SUPPLEMENTARY FigURES}

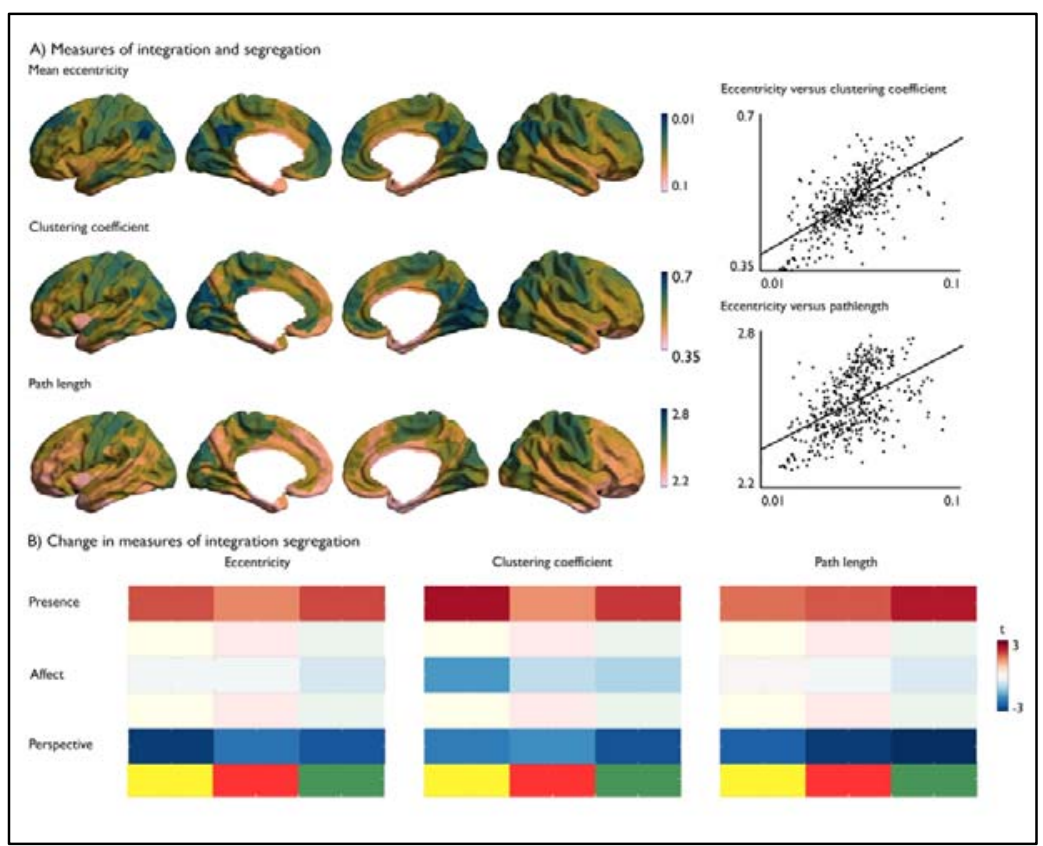

3 Figure S1. Comparison of gradient-based eccentricity measure with graph theory-based measures of 4 integration and segregation. A) Measures of integration and segregation; B) Change in difference measures of integration and segregation (clustering coefficient and path length). Colors reflect the relevant task-based network (yellow is attention, red is socio-affect and green is socio-cognition).

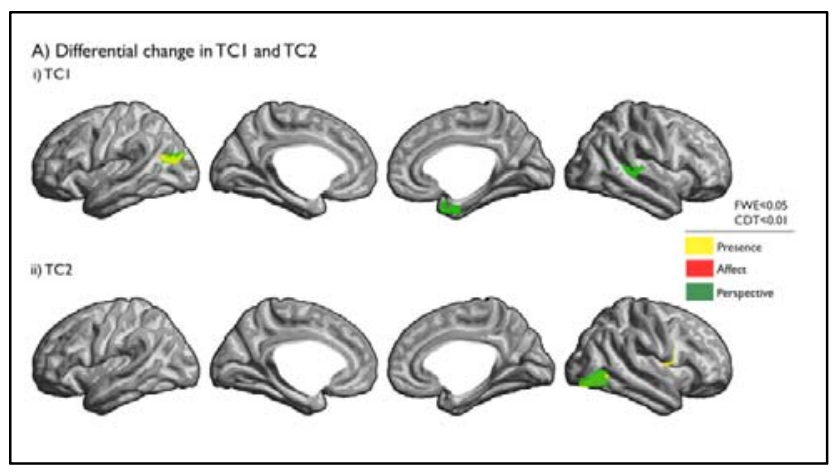

Figure S2. Module specific change in eccentricity in TC1 and TC2 separately. Whole brain differential change of manifold embedding in training cohort 1 (TC1) (i) and training cohort 2 (TC2) (ii), FWEp $<0.01$ twotailed following each training versus the other two trainings 
bioRxiv preprint doi: https://doi.org/10.1101/2020.11.11.377895; this version posted June 7, 2021. The copyright holder for this preprint (which was not certified by peer review) is the author/funder, who has granted bioRxiv a license to display the preprint in perpetuity. It is made available under aCC-BY-NC-ND 4.0 International license.

Valk et al. | Changing the social brain

A) Baseline embedding of task based networks
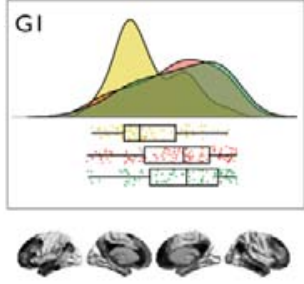
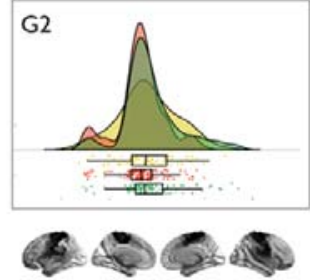
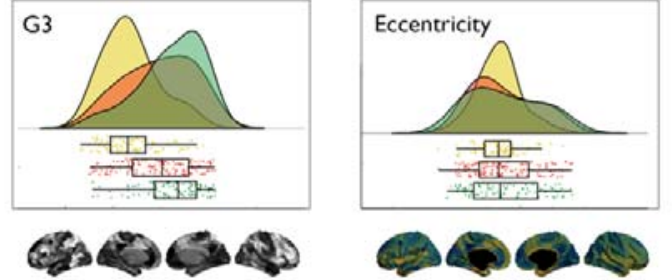

B) Module specific change
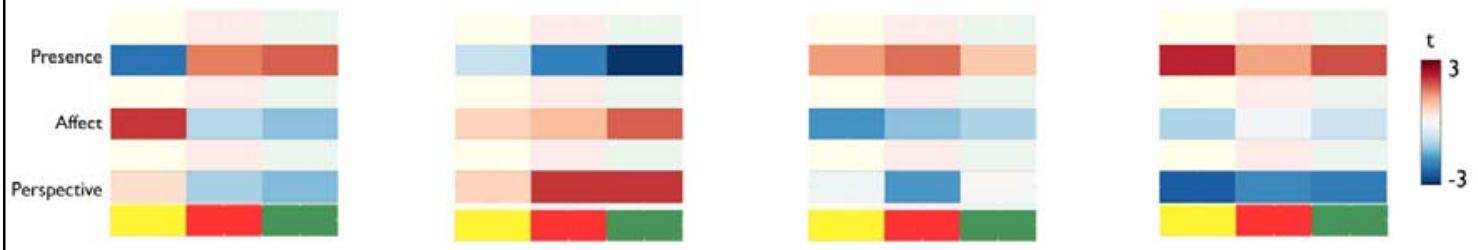

Figure S3. Large-scale organization of social brain and plasticity following training when controlling for GSR. Colors reflect the task-based networks.

A) Decomposition of social localizers in large-scale networks at rest
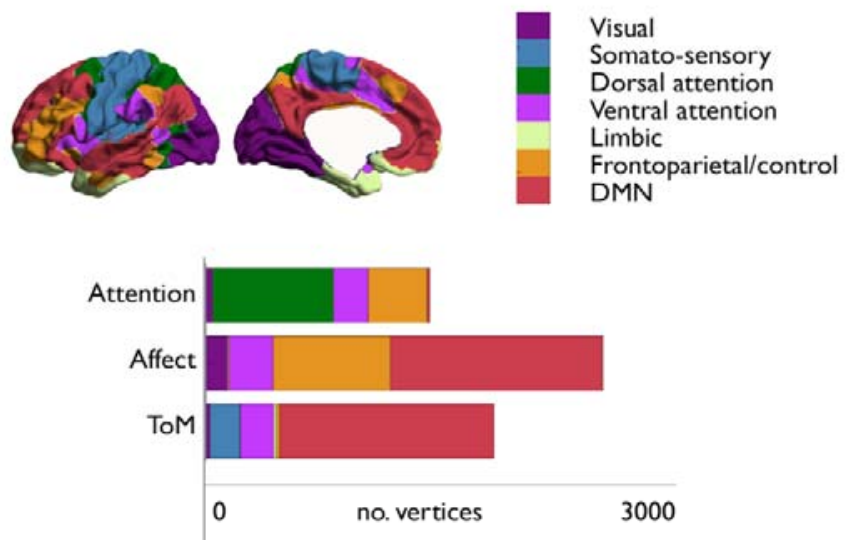

B) Module-specific change in large-scale functional communities

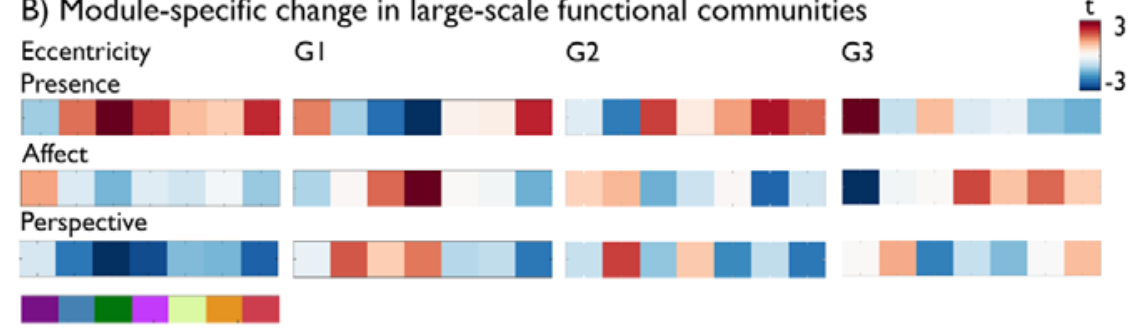

Figure S4. Functional community decoding. A) Decomposition of task-based functional activations into largescale functional community's at rest (Yeo et al., 2011); B) Association between the change in embedding, and the first three gradients, of large-scale functional communities (Yeo et al., 2011) following mental training. 
bioRxiv preprint doi: https://doi.org/10.1101/2020.11.11.377895; this version posted June 7, 2021. The copyright holder for this preprint (which was not certified by peer review) is the author/funder, who has granted bioRxiv a license to display the preprint in perpetuity. It is made available under aCC-BY-NC-ND 4.0 International license.

Valk et al. | Changing the social brain

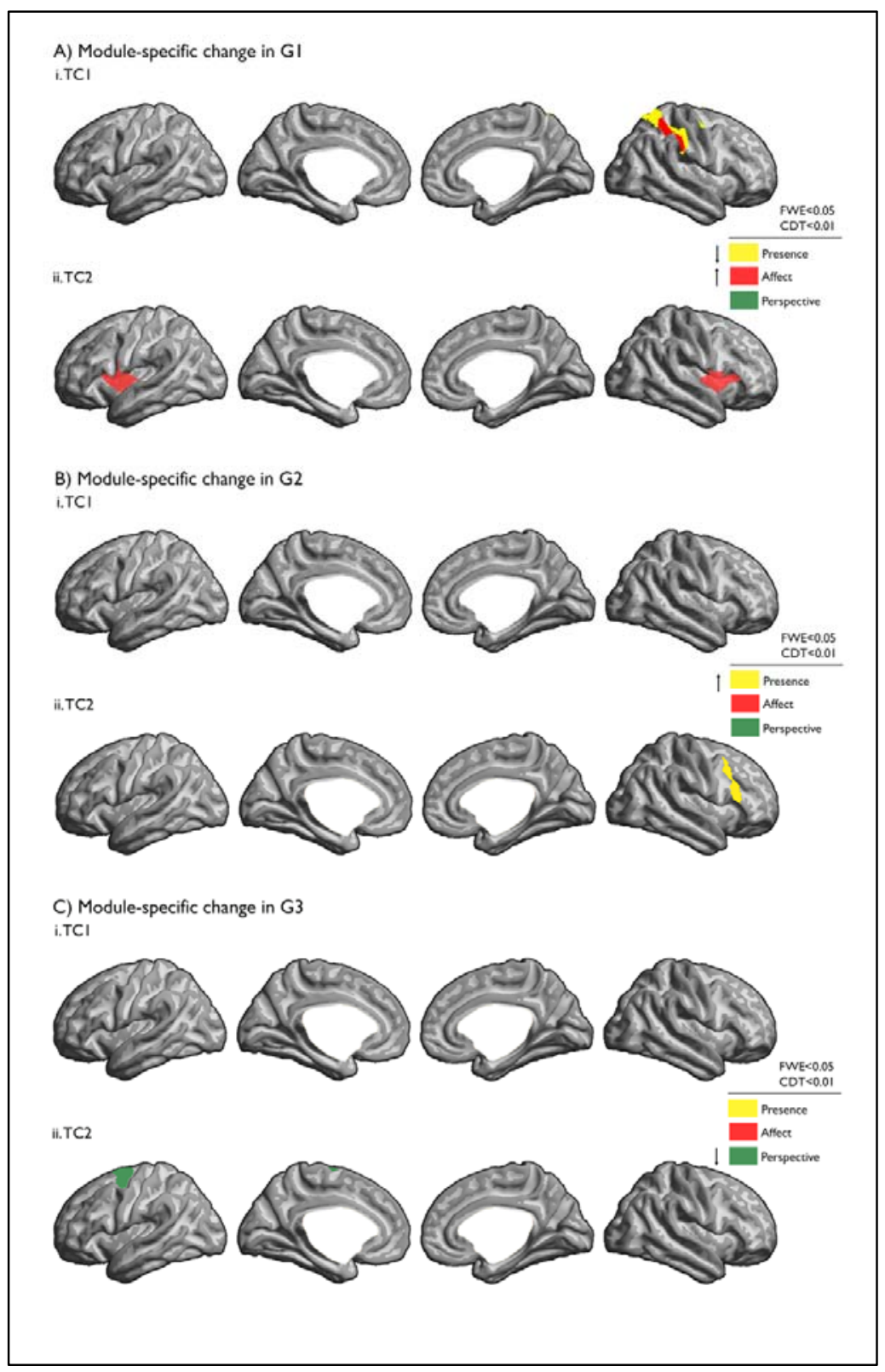

2 Figure S5. Gradient changes in TC1 and TC2 separately. Change in G1-G3 in training cohort 1 and 2 , 3 evaluated using a cortex-wide analysis, as well as within task-based networks. 
bioRxiv preprint doi: https://doi.org/10.1101/2020.11.11.377895; this version posted June 7, 2021. The copyright holder for this preprint (which was not certified by peer review) is the author/funder, who has granted bioRxiv a license to display the preprint in perpetuity. It is made available under aCC-BY-NC-ND 4.0 International license.

Valk et al. | Changing the social brain

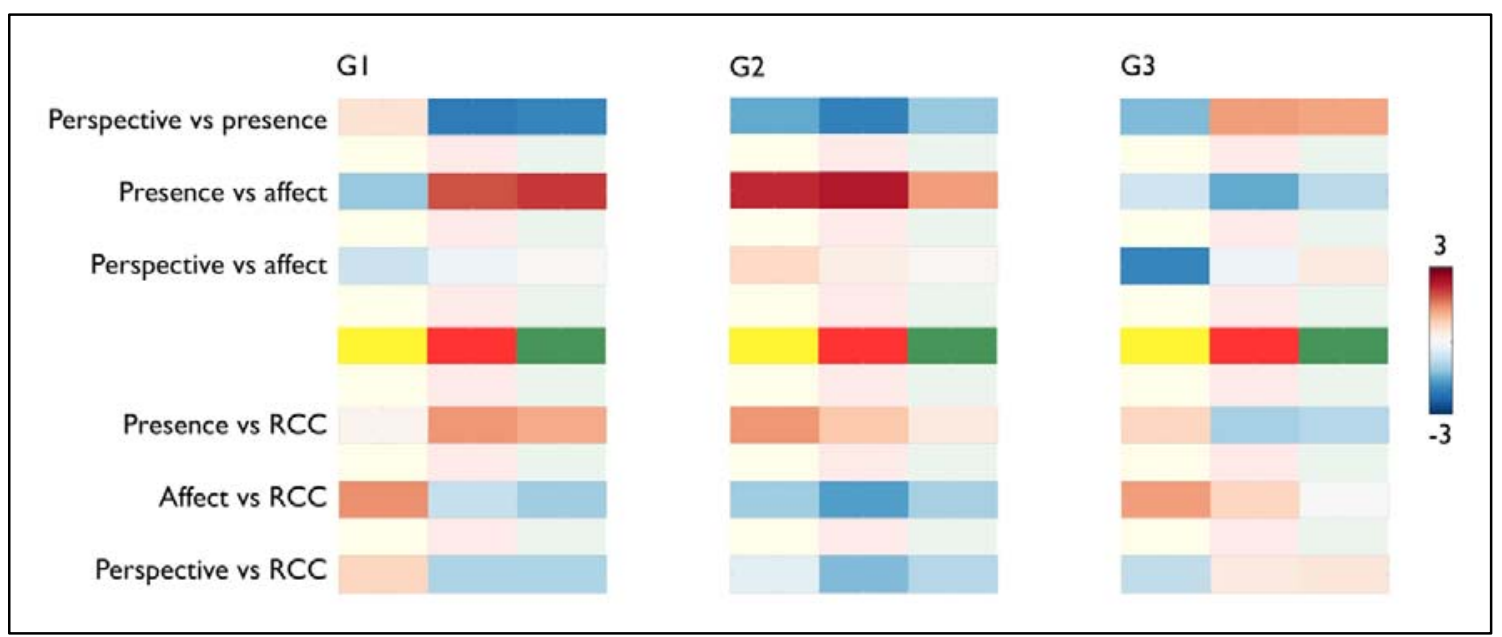

Figure S6. Change in G1-G3 vs other module and retest controls. Colors (yellow, red, green) reflect taskbased network (attention, socio-affect and socio-cognition respectively), whereas red-blue ([-3 3]) indicates the $\mathrm{t}$-value associated with change in each task-based network.

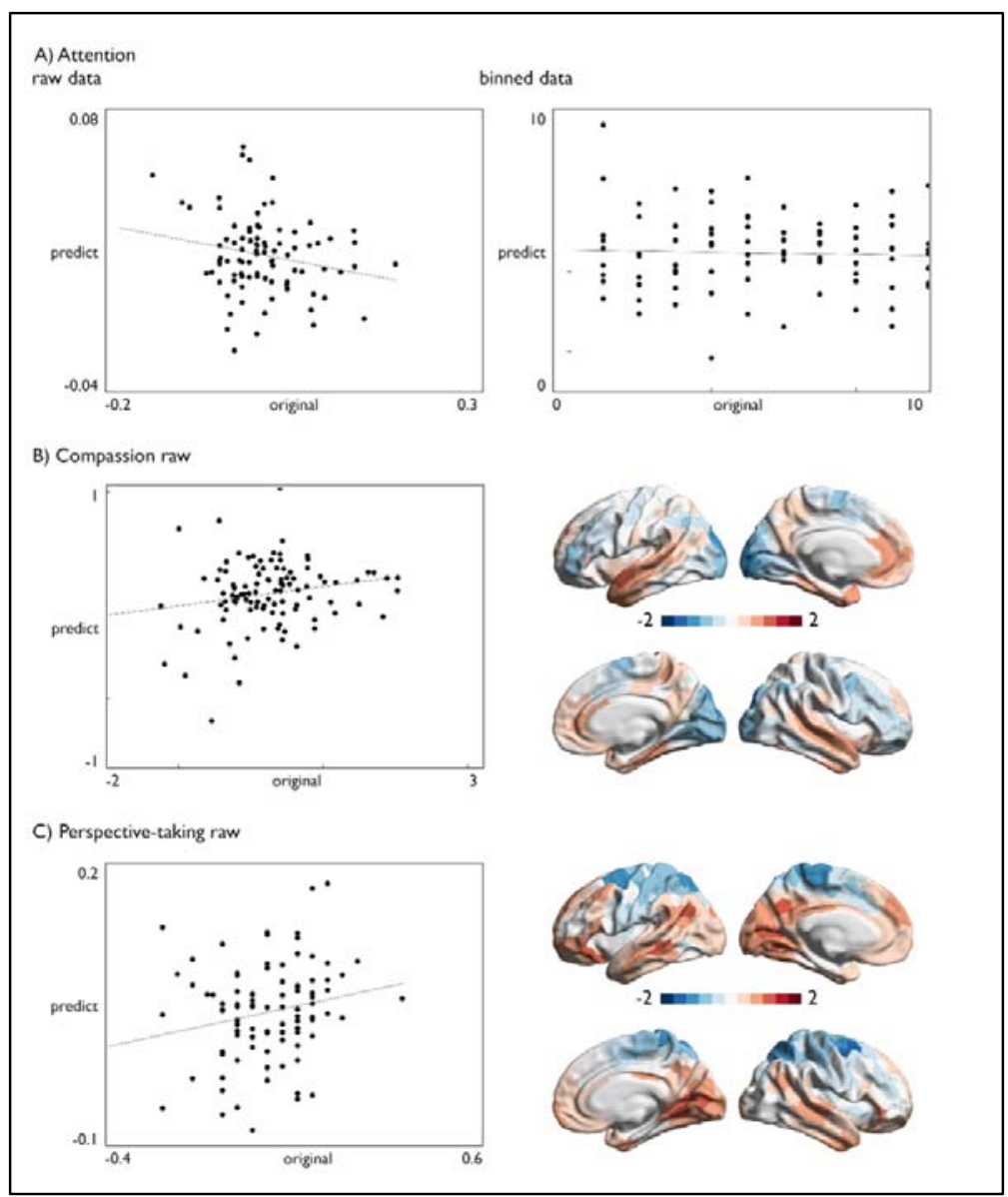

Figure S7. Predicting attention, compassion and ToM. A) Prediction of attention using raw and binned scores; B) Prediction of compassion and perspective-taking using raw change scores, as well as the associated weight maps (z-scored weights between -22 are visualized). 
Valk et al. | Changing the social brain

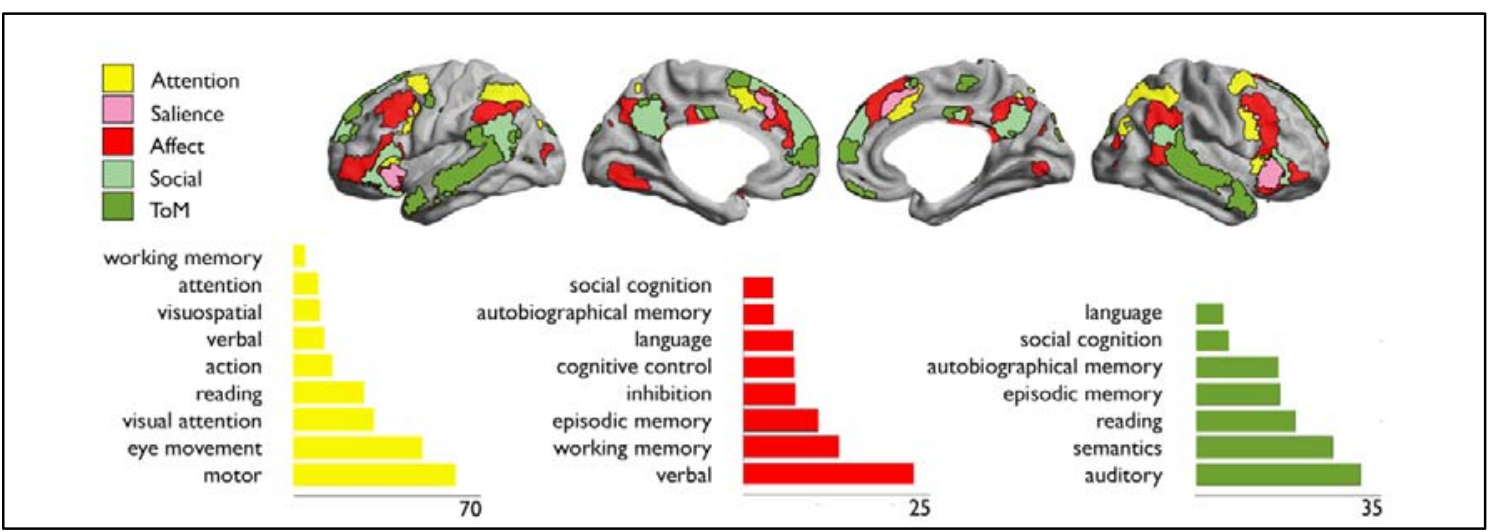

2 Figure S8. Functional decoding of task-based activations associated with attention, using 20 meta-analytical 3 topic terms of Neurosynth reflecting social, affective, cognitive, and attentional functioning. Significant 4 associations and associated t-values are represented in the bar plot, where yellow is attention, red is socio5 affective, and green is socio-cognitive task-based activation maps.

A) Developmental enrichment of attention task-based activation

$1.5 \log (\mathrm{p}) \quad 0$

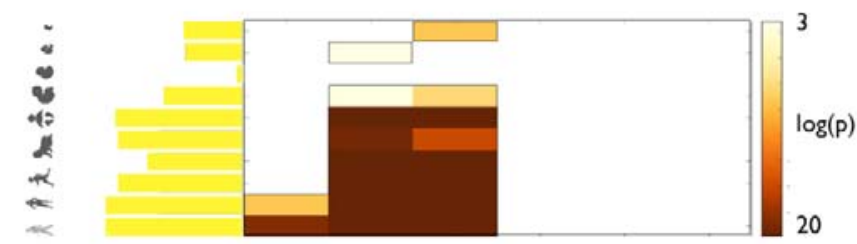

B) Developmental enrichment of socio-affective task-based activation

$1.5 \quad \log (p) \quad 0$

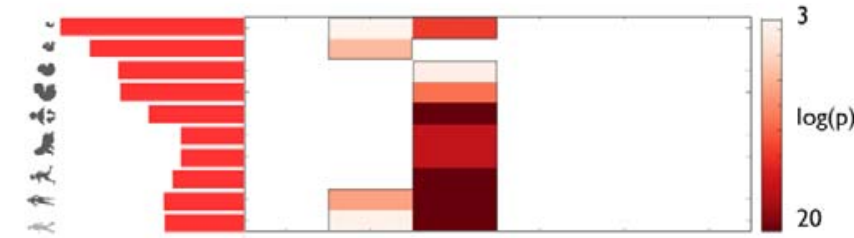

C) Developmental enrichment of socio-cognitive task-based activation $1.5 \quad \log (p) \quad 0$

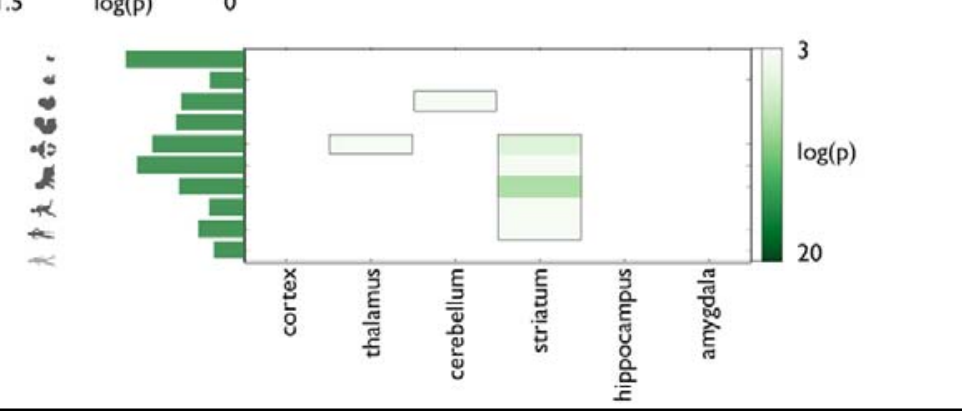

9 Figure S9. Developmental enrichment for each of the functional activations in attention, socio-affective, and 10 socio-cognitive tasks at FDRp $<0.05$. The bar plot on the represents the log transformed p-values that averaged across all brain structures that reported in the enrichment analysis. 
bioRxiv preprint doi: https://doi.org/10.1101/2020.11.11.377895; this version posted June 7, 2021. The copyright holder for this preprint (which was not certified by peer review) is the author/funder, who has granted bioRxiv a license to display the preprint in perpetuity. It is made available under aCC-BY-NC-ND 4.0 International license.

Valk et al. | Changing the social brain

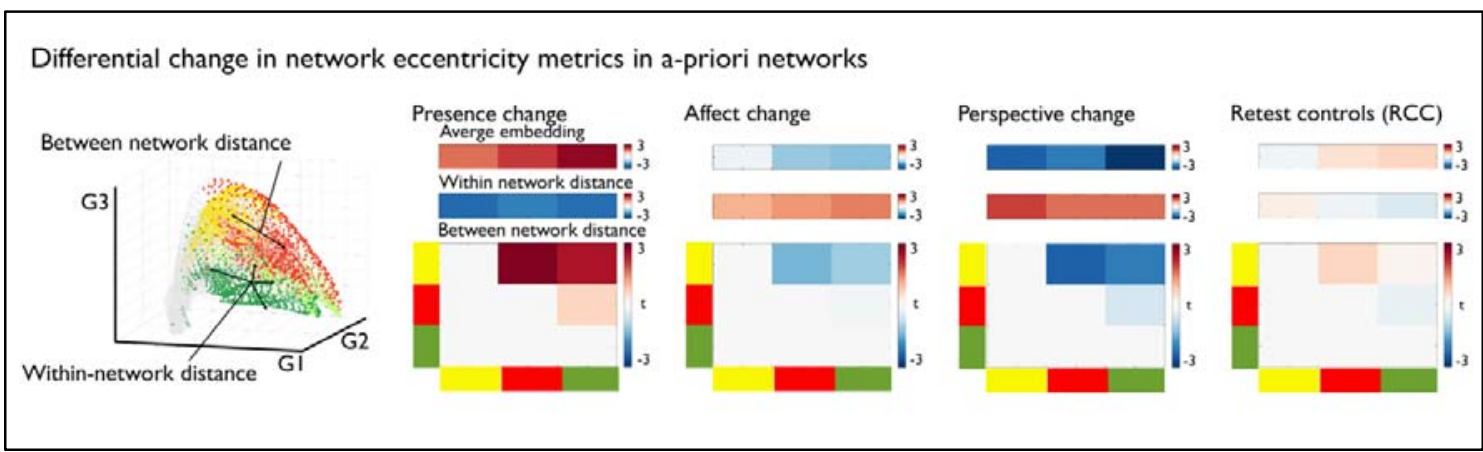

Figure S10. Differential change in eccentricity using network-based approaches. Average embedding recapitulates the average change score, within-network distance describes the change within each task-based network (yellow=attention, red=socio-affect, green=socio-cognition), between-network distance describes the change between task-based network. Effects are displayed as colored t-values [-3 3].

\section{A) Association with module-specific change}

Negative versus positive
thoughts

Negative versus positive
thoughts

Quiett versus busy

$$
-3
$$

$-3$

mind

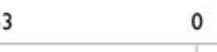

0

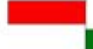

Other versus self

Past versus Future

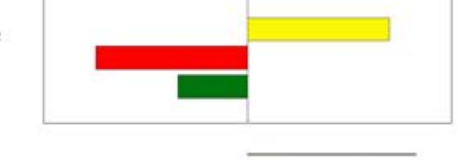

Presence

Affect

Perspective
B) Change in thought probes and functional organization

Quiet vs busy mind Negative vs positive

Averge embedding Averge embedding

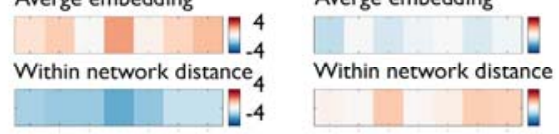

Between network distance Between network distance

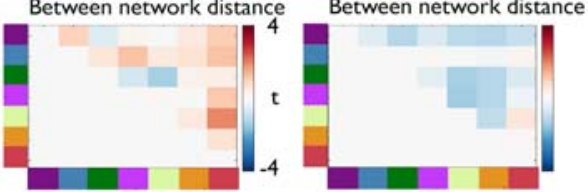

Other versus self Averge embedding Within network distance

Within network distance Averge embedding Within network distance

distance
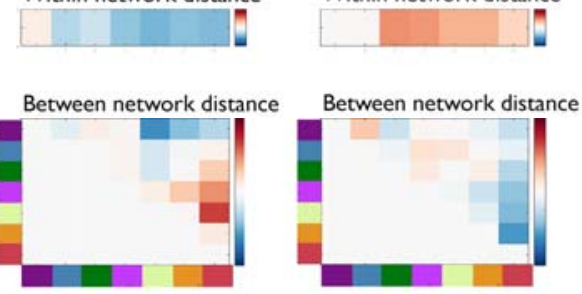

Figure S11 Association between change in task-unrelated thoughts and functional embedding. Change in task-related thought probes per module, and association with functional organization. 
bioRxiv preprint doi: https://doi.org/10.1101/2020.11.11.377895; this version posted June 7, 2021. The copyright holder for this preprint (which was not certified by peer review) is the author/funder, who has granted bioRxiv a license to display the preprint in perpetuity. It is made available under aCC-BY-NC-ND 4.0 International license.

Valk et al. | Changing the social brain

\section{SUPPLEMENTARY TABLES}

\begin{tabular}{|c|c|c|c|c|c|}
\hline ACAN & DCUN1D2 & GPX3 & MAP3K13 & PVALB & SULF1 \\
\hline ACYP2 & DENND2D & GSTT1 & MAP9 & QRFPR & SV2C \\
\hline $\mathrm{ADM}$ & DEXI & GUCA2B & MCF2 & RAB37 & SYCP2 \\
\hline ALDH1A3 & DNAJC4 & HAPLN4 & MFGE8 & RAD54B & SYT2 \\
\hline AMDHD1 & DSCC1 & HR & MGST2 & RAMP3 & TFAM \\
\hline ANK1 & ECSIT & HS3ST1 & MIR31HG & RCAN2 & THAP10 \\
\hline ANKRD34C & EFNA5 & HS3ST5 & MREG & RELL2 & TIFA \\
\hline AR & EIF5A2 & IGDCC3 & MX1 & RET & TPTE2P6 \\
\hline ARHGAP9 & ELMO3 & INA & MYH7B & RFPL1 & TRAK2 \\
\hline ASB13 & EPB41 & INTS8 & NEFH & RHOBTB2 & TRPC3 \\
\hline ATG4D & EPN3 & IPW & NR1D2 & RILP & TTC39A \\
\hline AVPI1 & ERRFI1 & IRS1 & $\mathrm{NR} 3 \mathrm{C} 1$ & RORA & ТTC39B \\
\hline BCAT1 & ESRRG & ISCU & NRIP2 & RPP25 & UPP1 \\
\hline BTBD17 & EXTL2 & KCNA2 & NT5M & RSRC1 & VAV3 \\
\hline C17orf75 & FAM20A & KCNAB3 & NXPH3 & SAP30L & \\
\hline C3orf18 & FAM71E1 & $\mathrm{KCNC} 1$ & ONECUT1 & SCN1A & \\
\hline C6orf106 & FBLN7 & $\mathrm{KCNC} 3$ & ONECUT2 & SCN1B & \\
\hline CACNA2D2 & FBXO9 & КCTD9 & OPRM1 & SCRT1 & \\
\hline CAMK2D & FER1L4 & KNG1 & P2RX6 & SDSL & \\
\hline CAMK2G & FES & KRT31 & PAG1 & SEMA7A & \\
\hline $\mathrm{CCNI}$ & FGF18 & LAG3 & PCDH12 & SHD & \\
\hline CDH7 & FGF9 & LAMA2 & PCP4 & SIX4 & \\
\hline CDR2L & FLT3 & LAPTM4B & PGK1 & SLC16A6 & \\
\hline CDS1 & FNDC5 & LCP2 & PHLDA2 & SLC17A6 & \\
\hline CERK & FRAT1 & LGALS1 & PHYH & SLC25A5 & \\
\hline CITED2 & FSTL1 & LINC00473 & PLCB4 & SLC38A1 & \\
\hline CLEC2L & FSTL5 & LINC00515 & PLCH1 & SLC39A13 & \\
\hline CMYA5 & GAL & LRCH1 & PLEKHH3 & SLC39A14 & \\
\hline CNTN6 & GDPD1 & LRRC38 & PLXDC1 & SMPX & \\
\hline CPNE9 & GLS2 & LRRC3B & PNKD & SPAG4 & \\
\hline CRTAC1 & GPLD1 & LUZP1 & PPARGC1A & SPTSSB & \\
\hline CTXN3 & GPR137C & LYPLA1 & PPTC7 & ST8SIA1 & \\
\hline CUX1 & GPR161 & MADCAM1 & PSMD12 & STARD10 & \\
\hline
\end{tabular}


bioRxiv preprint doi: https://doi.org/10.1101/2020.11.11.377895; this version posted June 7, 2021. The copyright holder for this preprint (which was not certified by peer review) is the author/funder, who has granted bioRxiv a license to display the preprint in perpetuity. It is made available under aCC-BY-NC-ND 4.0 International license.

Valk et al. | Changing the social brain

1 Table S1. Genes associated with attention network activations.

\begin{tabular}{|l|l|l|l|l|l|}
\hline DCBLD2 & GPR68 & MAGI3 & PTCHD1 & STARD5 & \\
\hline
\end{tabular}

\begin{tabular}{|l|l|l|l|l|l|}
\hline ALDH1 A3 & CITED2 & FSTL5 & IPW & PAG1 & SCN9A \\
AMDHD1 & CNTN6 & FZD1 & KCTD12 & PGAP1 & SLC38A1 \\
ANK1 & DCUN1D2 & GPLD1 & KLK10 & PLCB4 & SPON2 \\
ANKRD34C & DENND2D & GPR137C & LRCH1 & PLEKHH3 & ST8SIA1 \\
ANKRD6 & EPB41 & GPR68 & N4BP2 & PLSCR4 & TGFBI \\
CACNA2D2 & FABP7 & GPX3 & NANOS1 & PLXNC1 & TMEM159 \\
CADM1 & FLT3 & HIST1H1D & NGB & RAVER2 & UPP1 \\
CAMK2D & FNDC5 & IGDCC3 & ONECUT1 & RORA & WTIP \\
CDH7 & FRAT1 & INTS8 & OPRM1 & SCGN & \\
\hline
\end{tabular}

2

Table S2. Genes associated with compassion network activations

3

\begin{tabular}{|l|l|l|l|l|}
\hline BSPRY & FER1L4 & LRRC49 & ONECUT2 & SV2C \\
BTBD17 & HS3ST5 & LRRN1 & PCP4L1 & TRPC3 \\
COCH & IPW & MGST2 & RBMS1 & VAV3 \\
EIF2A & ITM2A & MRPL33 & S100A13 & WDR6 \\
FABP6 & KLHL13 & NCOA3 & SLC39A13 & ZNF268 \\
FANCI & LCA5 & NEB & SRGAP1 & \\
\hline
\end{tabular}

4 Table S3. Genes associated with perspective-taking functional activations

5

6 
bioRxiv preprint doi: https://doi.org/10.1101/2020.11.11.377895; this version posted June 7, 2021. The copyright holder for this preprint (which

was not certified by peer review) is the author/funder, who has granted bioRxiv a license to display the preprint in perpetuity. It is made available under aCC-BY-NC-ND 4.0 International license.

Valk et al. | Changing the social brain

\section{SUPPLEMENTARY REFERENCES}

2 Alcala-Lopez, D., Smallwood, J., Jefferies, E., Van Overwalle, F., Vogeley, K., Mars, R.B.,

3 Turetsky, B.I., Laird, A.R., Fox, P.T., Eickhoff, S.B., and Bzdok, D. (2018). Computing the

4 Social Brain Connectome Across Systems and States. Cereb Cortex 28, 2207-2232.

5 Alcala-Lopez, D., Vogeley, K., Binkofski, F., and Bzdok, D. (2019). Building blocks of social

6 cognition: Mirror, mentalize, share? Cortex 118, 4-18.

7 Alves, P.N., Foulon, C., Karolis, V., Bzdok, D., Margulies, D.S., Volle, E., and Thiebaut de

8 Schotten, M. (2019). An improved neuroanatomical model of the default-mode network

9 reconciles previous neuroimaging and neuropathological findings. Commun Biol 2, 370.

10 Arnatkeviciute, A., Fulcher, B.D., and Fornito, A. (2019). A practical guide to linking brain-

11 wide gene expression and neuroimaging data. Neuroimage 189, 353-367.

12 Assem, M., Glasser, M.F., Van Essen, D.C., and Duncan, J. (2020). A Domain-General Cognitive Core Defined in Multimodally Parcellated Human Cortex. Cereb Cortex 30, 43614380.

Barrett, L.F. (2017). The theory of constructed emotion: an active inference account of interoception and categorization. Soc Cogn Affect Neurosci 12, 1-23.

Barrett, L.F., and Satpute, A.B. (2013). Large-scale brain networks in affective and social neuroscience: towards an integrative functional architecture of the brain. Current opinion in neurobiology 23, 361-372.

Batson, C.D. (2009). These things called empathy. In The Social Neuroscience of Empathy, J. Decety, and W. Ickes, eds. (Cambridge, MA: MIT press), pp. 16-31.

Benjamini, Y., and Hochberg, Y. (1995). Controlling the False Discovery Rate: A Practical and Powerful Approach to Multiple Testing. Journal of the Royal Statistical Society Series B (Methodological) 57, 289-300.

Bertolero, M.A., Yeo, B.T., and D'Esposito, M. (2015). The modular and integrative functional architecture of the human brain. Proc Natl Acad Sci U S A 112, E6798-6807.

Bertolero, M.A., Yeo, B.T.T., and D'Esposito, M. (2017). The diverse club. Nat Commun 8, 1277.

Bethlehem, R.A.I., Paquola, C., Seidlitz, J., Ronan, L., Bernhardt, B.C., Consortium, C.-C., and Tsvetanov, K.A. (2020). Dispersion of functional gradients across the lifespan. NeuroImage

Betzel, R.F., Fukushima, M., He, Y., Zuo, X.N., and Sporns, O. (2016). Dynamic fluctuations coincide with periods of high and low modularity in resting-state functional brain networks. Neuroimage 127, 287-297.

Buckner, R.L., Andrews-Hanna, J.R., and Schacter, D.L. (2008). The brain's default network: anatomy, function, and relevance to disease. Ann N Y Acad Sci 1124, 1-38.

Bzdok, D., Schilbach, L., Vogeley, K., Schneider, K., Laird, A.R., Langner, R., and Eickhoff, S.B. (2012). Parsing the neural correlates of moral cognition: ALE meta-analysis on morality, theory of mind, and empathy. Brain Struct Funct 217, 783-796.

Chanes, L., and Barrett, L.F. (2016). Redefining the Role of Limbic Areas in Cortical Processing. Trends Cogn Sci 20, 96-106.

Chang, L.J., Gianaros, P.J., Manuck, S.B., Krishnan, A., and Wager, T.D. (2015). A Sensitive and Specific Neural Signature for Picture-Induced Negative Affect. PLoS Biol 13, e1002180. Chun, M.M., Golomb, J.D., and Turk-Browne, N.B. (2011). A taxonomy of external and internal attention. Annu Rev Psychol 62, 73-101.

Coifman, R.R., Lafon, S., Lee, A.B., Maggioni, M., Nadler, B., Warner, F., and Zucker, S.W. (2005). Geometric diffusions as a tool for harmonic analysis and structure definition of data: diffusion maps. Proc Natl Acad Sci U S A 102, 7426-7431.

Corbetta, M., Patel, G., and Shulman, G.L. (2008). The reorienting system of the human brain: from environment to theory of mind. Neuron 58, 306-324. 
bioRxiv preprint doi: https://doi.org/10.1101/2020.11.11.377895; this version posted June 7, 2021. The copyright holder for this preprint (which

was not certified by peer review) is the author/funder, who has granted bioRxiv a license to display the preprint in perpetuity. It is made

Valk et al. | Changing the social brain

1 Corbetta, M., and Shulman, G.L. (2002). Control of goal-directed and stimulus-driven

2 attention in the brain. Nat Rev Neurosci 3, 201-215.

3 Cotier, F.A., Zhang, R., and Lee, T.M.C. (2017). A longitudinal study of the effect of short-

4 term meditation training on functional network organization of the aging brain. Sci Rep 7,

5598 .

6 Craig, A.D. (2009). How do you feel--now? The anterior insula and human awareness. Nat

7 Rev Neurosci 10, 59-70.

8 Dajani, D.R., and Uddin, L.Q. (2015). Demystifying cognitive flexibility: Implications for

9 clinical and developmental neuroscience. Trends Neurosci 38, 571-578.

10 Dale, A.M., Fischl, B., and Sereno, M.I. (1999). Cortical surface-based analysis. I.

11 Segmentation and surface reconstruction. Neuroimage 9, 179-194.

12 de Vignemont, F., and Singer, T. (2006). The empathic brain: how, when and why? Trends

13 Cogn Sci 10, 435-441.

14 de Waal, F.B. (2012). The antiquity of empathy. Science 336, 874-876.

15 Dehaene, S., Kerszberg, M., and Changeux, J.P. (1998). A neuronal model of a global

16 workspace in effortful cognitive tasks. Proc Natl Acad Sci U S A 95, 14529-14534.

17 Dougherty, J.D., Schmidt, E.F., Nakajima, M., and Heintz, N. (2010). Analytical approaches

18 to RNA profiling data for the identification of genes enriched in specific cells. Nucleic Acids

19 Res 38, 4218-4230.

20 Dunbar, R.I.M. (1998). The Social Brain hypothesis. Evol Anthropol 6, 178-190.

21 Duncan, J. (2010). The multiple-demand (MD) system of the primate brain: mental programs

22 for intelligent behaviour. Trends Cogn Sci 14, 172-179.

23 Eisenberg, N., and Fabes, R.A. (1990). Empathy: conceptualization, measurement, and 24 relation to prosocial behavior. . Motivation and Emotion 14, 131-149. (2020). Dynamic reconfiguration of functional brain networks during working memory training. Nat Commun 11, 2435.

First, M.B., Gibbon, M., Spitzer, R.L., Williams, J.B.W., and Benjamin, L.S. (1997). Structured Clinical Interview for DSM-IV Axis II Personality Disorders, (SCID-II). (Washington, D.C.: American psychiatric Press, Inc.).

Frith, C.D., and Frith, U. (2006). The neural basis of mentalizing. Neuron 50, 531-534.

Frith, U., and Frith, C.D. (2003). Development and neurophysiology of mentalizing. Philos Trans R Soc Lond B Biol Sci 358, 459-473.

Gorgolewski, K.J., Fox, A.S., Chang, L.J., Schaefer, A., Arelin, K., Burmann, I., Sacher, J., and Margulies, D.S. (2014). Tight fitting genes: finding relations between statistical maps and gene expression patterns. In OHBM 2014.

Gratton, C., Laumann, T.O., Nielsen, A.N., Greene, D.J., Gordon, E.M., Gilmore, A.W., Nelson, S.M., Coalson, R.S., Snyder, A.Z., Schlaggar, B.L., et al. (2018). Functional Brain Networks Are Dominated by Stable Group and Individual Factors, Not Cognitive or Daily Variation. Neuron 98, 439-452 e435.

Haak, K.V., and Beckmann, C.F. (2020). Understanding brain organisation in the face of functional heterogeneity and functional multiplicity. Neuroimage 220, 117061.

Haak, K.V., Marquand, A.F., and Beckmann, C.F. (2018). Connectopic mapping with restingstate fMRI. Neuroimage 170, 83-94.

Hansen, J.Y., Markello, R.D., Vogel, J.W., Seidlitz, J., Bzdok, D., and Misic, B. (2021). Mapping gene transcription and neurocognition across human neocortex. Nat Hum Behav.

Hawrylycz, M.J., Lein, E.S., Guillozet-Bongaarts, A.L., Shen, E.H., Ng, L., Miller, J.A., van de Lagemaat, L.N., Smith, K.A., Ebbert, A., Riley, Z.L., et al. (2012). An anatomically comprehensive atlas of the adult human brain transcriptome. Nature 489, 391-399.

50 Holmes, T. (2007). Parts word: An illustrated guide to your inner life (Kalamazoo: Winged 51 Heart Press). 
bioRxiv preprint doi: https://doi.org/10.1101/2020.11.11.377895; this version posted June 7, 2021. The copyright holder for this preprint (which

was not certified by peer review) is the author/funder, who has granted bioRxiv a license to display the preprint in perpetuity. It is made

Valk et al. | Changing the social brain

1 Hong, S.J., Vos de Wael, R., Bethlehem, R.A.I., Lariviere, S., Paquola, C., Valk, S.L.,

2 Milham, M.P., Di Martino, A., Margulies, D.S., Smallwood, J., and Bernhardt, B.C. (2019).

3 Atypical functional connectome hierarchy in autism. Nat Commun 10, 1022.

4 Hong, S.J., Xu, T., Nikolaidis, A., Smallwood, J., Margulies, D.S., Bernhardt, B.C., 5 Vogelstein, J.T., and Milham, M.P. (2020). Towards a connectivity gradient-based 6 frameworrk for reproducible biomarker discovery. bioRxiv

7 Huntenburg, J.M., Bazin, P.L., Goulas, A., Tardif, C.L., Villringer, A., and Margulies, D.S.

8 (2017). A Systematic Relationship Between Functional Connectivity and Intracortical Myelin

9 in the Human Cerebral Cortex. Cereb Cortex 27, 981-997.

10 Huntenburg, J.M., Bazin, P.L., and Margulies, D.S. (2018). Large-Scale Gradients in Human

11 Cortical Organization. Trends Cogn Sci 22, 21-31.

12 Kabat-Zinn, J. (1990). Full catastrophe living: using the wisdom of your body and mind to

13 face stress, pain, and illness. (New York, NY: Delacorte).

14 Kanske, P., Bockler, A., Trautwein, F.M., and Singer, T. (2015). Dissecting the social brain:

15 Introducing the EmpaToM to reveal distinct neural networks and brain-behavior relations for

16 empathy and Theory of Mind. Neuroimage 122, 6-19.

17 Kernbach, J.M., Yeo, B.T.T., Smallwood, J., Margulies, D.S., Thiebaut de Schotten, M.,

18 Walter, H., Sabuncu, M.R., Holmes, A.J., Gramfort, A., Varoquaux, G., et al. (2018).

19 Subspecialization within default mode nodes characterized in 10,000 UK Biobank

20 participants. Proc Natl Acad Sci U S A 115, 12295-12300.

21 Kleckner, I.R., Zhang, J., Touroutoglou, A., Chanes, L., Xia, C., Simmons, W.K., Quigley,

22 K.S., Dickerson, B.C., and Barrett, L.F. (2017). Evidence for a Large-Scale Brain System

23 Supporting Allostasis and Interoception in Humans. Nat Hum Behav 1.

24 Klimecki, O.M., Leiberg, S., Ricard, M., and Singer, T. (2014). Differential pattern of

25 functional brain plasticity after compassion and empathy training. Soc Cogn Affect Neurosci 26 9, 873-879.

27 Kok, B.E., and Singer, T. (2016). Effects of Contemplative Dyads on Engagement and 28 Perceived Social Connectedness Over 9 Months of Mental Training: A Randomized Clinical 29 Trial. JAMA Psychiatry.

30 Lamm, C., Decety, J., and Singer, T. (2011). Meta-analytic evidence for common and distinct 31 neural networks associated with directly experienced pain and empathy for pain. Neuroimage $3254,2492-2502$.

33 Lutz, A., Mattout, J., and Pagnoni, G. (2019). The epistemic and pragmatic value of non34 action: a predictive coding perspective on meditation. Curr Opin Psychol 28, 166-171. Margulies, D.S., Ghosh, S.S., Goulas, A., Falkiewicz, M., Huntenburg, J.M., Langs, G., Bezgin, G., Eickhoff, S.B., Castellanos, F.X., Petrides, M., et al. (2016). Situating the defaultmode network along a principal gradient of macroscale cortical organization. Proc Natl Acad Sci U S A 113, 12574-12579.

Menon, V. (2015). Salience Network. In Brain Mapping: An Encyclopedic Reference, A.W. Toga, ed. (Academic Press: Elsevier), pp. 597-611.

Menon, V., and Uddin, L.Q. (2010). Saliency, switching, attention and control: a network model of insula function. Brain Struct Funct 214, 655-667.

Mesulam, M.M. (1998). From sensation to cognition. Brain 121 ( Pt 6), 1013-1052.

Murphy, C., Jefferies, E., Rueschemeyer, S.A., Sormaz, M., Wang, H.T., Margulies, D.S., and Smallwood, J. (2018). Distant from input: Evidence of regions within the default mode network supporting perceptually-decoupled and conceptually-guided cognition. Neuroimage 171, 393-401.

Murphy, C., Wang, H.T., Konu, D., Lowndes, R., Margulies, D.S., Jefferies, E., and Smallwood, J. (2019). Modes of operation: A topographic neural gradient supporting stimulus 
bioRxiv preprint doi: https://doi.org/10.1101/2020.11.11.377895; this version posted June 7, 2021. The copyright holder for this preprint (which

was not certified by peer review) is the author/funder, who has granted bioRxiv a license to display the preprint in perpetuity. It is made available under aCC-BY-NC-ND 4.0 International license.

Valk et al. | Changing the social brain

1 Neff, K.D., and Germer, C.K. (2013). A pilot study and randomized controlled trial of the

2 mindful self-compassion program. J Clin Psychol 69, 28-44.

3 Ochsner, K.N., and Lieberman, M.D. (2001). The emergence of social cognitive 4 neuroscience. Am Psychol 56, 717-734.

5 Paquola, C., Benkarim, O., DeKraker, J., Lariviere, S., Frassle, S., Royer, J., Tavakol, S.,

6 Valk, S., Bernasconi, A., Bernasconi, N., et al. (2020a). Convergence of cortical types and

7 functional motifs in the human mesiotemporal lobe. Elife 9.

8 Paquola, C., Bethlehem, R.A.I., and Bernhardt, B.C. (2020b). A moment of change: shifts in

9 myeloarchitecture characterise adolescent development of cortical gradients. eLife.

10 Paquola, C., Vos De Wael, R., Wagstyl, K., Bethlehem, R.A.I., Hong, S.J., Seidlitz, J.,

11 Bullmore, E.T., Evans, A.C., Misic, B., Margulies, D.S., et al. (2019). Microstructural and

12 functional gradients are increasingly dissociated in transmodal cortices. PLoS Biol 17,

13 e3000284.

14 Park, B., Bethlehem, R.A.I., Paquola, C., Lariviere, S., Cruces, R.R., Vos De Wael, R.,

15 Consortium, N.i.P.N., Bullmore, E.T., and Bernhardt, B.C. (2020). Macroscale connectome

16 manifold expansion in adolescence. bioRxiv

17 Pernet, C.R., Belov, N., Delorme, A., and Zammit, A. (2021). Mindfulness related changes in

18 grey matter: a systematic review and meta-analysis. Brain Imaging Behav.

19 Pessoa, L. (2014). Understanding brain networks and brain organization. Phys Life Rev 11,

$20 \quad 400-435$.

21 Pinheiro, J.C., and Bates, D. (2000). Mixed-effect models in S and S-PLUS (Springer). Power, J.D., Barnes, K.A., Snyder, A.Z., Schlaggar, B.L., and Petersen, S.E. (2012). Spurious but systematic correlations in functional connectivity MRI networks arise from subject motion. Neuroimage 59, 2142-2152.

Preston, S.D., and de Waal, F.B. (2002). Empathy: Its ultimate and proximate bases. Behav Brain Sci 25, 1-20; discussion 20-71.

Raz, G., Touroutoglou, A., Wilson-Mendenhall, C., Gilam, G., Lin, T., Gonen, T., Jacob, Y., Atzil, S., Admon, R., Bleich-Cohen, M., et al. (2016). Functional connectivity dynamics during film viewing reveal common networks for different emotional experiences. Cogn Affect Behav Neurosci 16, 709-723.

Rubinov, M., and Sporns, O. (2010). Complex network measures of brain connectivity: uses and interpretations. Neuroimage 52, 1059-1069.

Salzberg, D. (1995). Lovingkindness. The Revolutionary Art of Happiness. (Boston, MA: Shambala).

Saxe, R., and Kanwisher, N. (2003). People thinking about thinking people. The role of the temporo-parietal junction in "theory of mind". Neuroimage 19, 1835-1842.

Schaafsma, S.M., Pfaff, D.W., Spunt, R.P., and Adolphs, R. (2015). Deconstructing and reconstructing theory of mind. Trends Cogn Sci 19, 65-72.

Schaefer, A., Kong, R., Gordon, E.M., Laumann, T.O., Zuo, X.N., Holmes, A.J., Eickhoff, S.B., and Yeo, B.T.T. (2018). Local-Global Parcellation of the Human Cerebral Cortex from Intrinsic Functional Connectivity MRI. Cereb Cortex 28, 3095-3114.

Schilbach, L., Timmermans, B., Reddy, V., Costall, A., Bente, G., Schlicht, T., and Vogeley, K. (2013). Toward a second-person neuroscience. Behav Brain Sci 36, 393-414.

Schurz, M., Maliske, L., and Kanske, P. (2020a). Cross-network interactions in social cognition: A review of findings on task related brain activation and connectivity. Cortex.

Schurz, M., Radua, J., Aichhorn, M., Richlan, F., and Perner, J. (2014). Fractionating theory of mind: a meta-analysis of functional brain imaging studies. Neurosci Biobehav Rev 42, 934.

Schurz, M., Radua, J., Tholen, M.G., Maliske, L., Margulies, D.S., Mars, R.B., Sallet, J., and

50 Kanske, P. (2020b). Toward a hierarchical model of social cognition: A neuroimaging metaanalysis and integrative review of empathy and theory of mind. Psychol Bull. 
bioRxiv preprint doi: https://doi.org/10.1101/2020.11.11.377895; this version posted June 7, 2021. The copyright holder for this preprint (which

was not certified by peer review) is the author/funder, who has granted bioRxiv a license to display the preprint in perpetuity. It is made

Valk et al. | Changing the social brain

1 Schwarz, R.C. (1997). Internal familly systems therapy. (New York: Guilford).

2 Shine, J.M. (2020). The thalamus integrates the macrosystems of the brain to facilitate

3 complex, adaptive brain network dynamics. Prog Neurobiol, 101951.

4 Shine, J.M., Aburn, M.J., Breakspear, M., and Poldrack, R.A. (2018). The modulation of

5 neural gain facilitates a transition between functional segregation and integration in the brain.

6 Elife 7.

7 Shine, J.M., Bissett, P.G., Bell, P.T., Koyejo, O., Balsters, J.H., Gorgolewski, K.J., Moodie,

8 C.A., and Poldrack, R.A. (2016). The Dynamics of Functional Brain Networks: Integrated

9 Network States during Cognitive Task Performance. Neuron 92, 544-554.

10 Shine, J.M., Breakspear, M., Bell, P.T., Ehgoetz Martens, K.A., Shine, R., Koyejo, O.,

11 Sporns, O., and Poldrack, R.A. (2019). Human cognition involves the dynamic integration of

12 neural activity and neuromodulatory systems. Nat Neurosci 22, 289-296.

13 Shine, J.M., and Poldrack, R.A. (2018). Principles of dynamic network reconfiguration across

14 diverse brain states. Neuroimage 180, 396-405.

15 Singer, T. (2006). The neuronal basis and ontogeny of empathy and mind reading: review of

16 literature and implications for future research. Neurosci Biobehav Rev 30, 855-863.

17 Singer, T. (2012). The past, present and future of social neuroscience: a European perspective.

18 Neuroimage 61, 437-449.

19 Singer, T., Kok, B.E., Bornemann, B., Zurborg, S., Bolz, M., and Bochow, C.A. (2016). The

20 ReSource Project. Background, design, samples and measurements (2nd ed).

21 Singer, T., and Lamm, C. (2009). The social neuroscience of empathy. Ann N Y Acad Sci 22 1156, 81-96.

23 Singer, T., Seymour, B., O'Doherty, J., Kaube, H., Dolan, R.J., and Frith, C.D. (2004).

24 Empathy for pain involves the affective but not sensory components of pain. Science 303,

25 1157-1162.

26 Smallwood, J., Turnbull, A., Wang, H.T., Ho, N.S.P., Poerio, G.L., Karapanagiotidis, T.,

27 Konu, D., McKeown, B., Zhang, M., Murphy, C., et al. (2021). The neural correlates of 28 ongoing conscious thought. iScience 24, 102132.

29 Song, C., Kanai, R., Fleming, S.M., Weil, R.S., Schwarzkopf, D.S., and Rees, G. (2011).

30 Relating inter-individual differences in metacognitive performance on different perceptual

31 tasks. Conscious Cogn 20, 1787-1792.

32 Sormaz, M., Murphy, C., Wang, H.T., Hymers, M., Karapanagiotidis, T., Poerio, G., 33 Margulies, D.S., Jefferies, E., and Smallwood, J. (2018). Default mode network can support 34 the level of detail in experience during active task states. Proc Natl Acad Sci U S A 115, 35 9318-9323.

36 Tang, Y.Y., Holzel, B.K., and Posner, M.I. (2015). The neuroscience of mindfulness 37 meditation. Nat Rev Neurosci 16, 213-225.

38 Tholen, M.G., Trautwein, F.M., Böckler, A., Singer, T., and Kanske, P. (2020). Functional 39 magnetic resonance imaging (fMRI) item analysis of empathy and theory of mind. Hum Brain 40 Mapp.

41 Tomasello, M. (1995). Joint atttention as social cognition. In Joint attentioon: Its origins and 42 role in development, C. Moore, and P.J. Dunham, eds. (LawrenceErlbaum Associates, Inc.), 43 pp. 103-130.

44 Trautwein, F.M., Kanske, P., Bockler, A., and Singer, T. (2020). Differential benefits of 45 mental training types for attention, compassion, and theory of mind. Cognition 194, 104039.

46 Trautwein, F.M., Singer, T., and Kanske, P. (2016). Stimulus-Driven Reorienting Impairs

47 Executive Control of Attention: Evidence for a Common Bottleneck in Anterior Insula. Cereb 48 Cortex.

49 Turnbull, A., Karapanagiotidis, T., Wang, H.T., Bernhardt, B.C., Leech, R., Margulies, D.,

50 Schooler, J., Jefferies, E., and Smallwood, J. (2020). Reductions in task positive neural 
bioRxiv preprint doi: https://doi.org/10.1101/2020.11.11.377895; this version posted June 7, 2021. The copyright holder for this preprint (which

was not certified by peer review) is the author/funder, who has granted bioRxiv a license to display the preprint in perpetuity. It is made

Valk et al. | Changing the social brain

1 systems occur with the passage of time and are associated with changes in ongoing thought.

2 Sci Rep 10, 9912.

3 Turnbull, A., Wang, H.T., Murphy, C., Ho, N.S.P., Wang, X., Sormaz, M., Karapanagiotidis, 4 T., Leech, R.M., Bernhardt, B., Margulies, D.S., et al. (2019a). Left dorsolateral prefrontal 5 cortex supports context-dependent prioritisation of off-task thought. Nat Commun 10, 3816.

6 Turnbull, A., Wang, H.T., Schooler, J.W., Jefferies, E., Margulies, D.S., and Smallwood, J. 7 (2019b). The ebb and flow of attention: Between-subject variation in intrinsic connectivity 8 and cognition associated with the dynamics of ongoing experience. Neuroimage 185, 2869299.

10 Uddin, L.Q. (2015). Salience processing and insular cortical function and dysfunction. Nat 11 Rev Neurosci 16, 55-61.

12 Valk, S.L., Bernhardt, B.C., Trautwein, F.M., Bockler, A., Kanske, P., Guizard, N., Collins, 13 D.L., and Singer, T. (2017). Structural plasticity of the social brain: Differential change after socio-affective and cognitive mental training. Sci Adv 3, e1700489.

Valk, S.L., Xu, T., Margulies, D.S., Kharabian Masouleh, S., Paquola, C., Goulas, A., Kochunov, P., Smallwood, J., Yeo, B.T., Bernhardt, B.C., and Eickhoff, S.B. (2020). Shaping Brain Structure: Genetic and Phylogenetic Axes of Macro Scale Organization of Cortical Thickness. Sci Adv.

Van Essen, D.C., Smith, S.M., Barch, D.M., Behrens, T.E., Yacoub, E., Ugurbil, K., and Consortium, W.U.-M.H. (2013). The WU-Minn Human Connectome Project: an overview. Neuroimage 80, 62-79.

Vos de Wael, R., Benkarim, O., Paquola, C., Lariviere, S., Royer, J., Tavakol, S., Xu, T., Hong, S.J., Valk, S.L., Misic, B., et al. (2020). BrainSpace: a toolbox for the analysis of macroscale gradients in neuroimaging and connectomics datasets. Nat Commun Biology.

Vos de Wael, R., Lariviere, S., Caldairou, B., Hong, S.J., Margulies, D.S., Jefferies, E., Bernasconi, A., Smallwood, J., Bernasconi, N., and Bernhardt, B.C. (2018). Anatomical and microstructural determinants of hippocampal subfield functional connectome embedding. Proc Natl Acad Sci U S A 115, 10154-10159.

Wittchen, H.U., and Pfister, H. (1997). Diagnostisches Expertensystem für psychische Störungen (DIA-X) (Frankfurt: Swets \& Zeitlinger).

Wittchen, H.U., Zaudig, M., and Fydrich, T. (1997). SKID-Strukturiertes Klinisches Interview für DSM-IV. Achse I und II (Göttingen: Hogrefe).

Worsley, K., Taylor, J.E., Carbonell, F., Chung, M.K., Duerden, E., Bernhardt, B.C., Lyttelton, O.C., Boucher, M., and Evans, A. (2009). SurfStat: A Matlab toolbox for the statistical analysis of univariate and multivariate surface and volumetric data using linear mixed effect models and random field theory. Neuroimage S102.

Worsley, K.J., Andermann, M., Koulis, T., MacDonald, D., and Evans, A.C. (1999). Detecting changes in nonisotropic images. Hum Brain Mapp 8, 98-101.

Xu, T., Nenning, K., Schwartz, E., Hong, S.J., Vogelstein, J.T., Fair, D.A., Schroeder, C.E., Margulies, D.S., Smallwood, J., Milham, M.P., and Langs, G. (2020). Cross-species Functional Alignment Reveals Evolutionary Hierarchy Within the Connectome. Neuroimage. Yarkoni, T., Poldrack, R.A., Nichols, T.E., Van Essen, D.C., and Wager, T.D. (2011). Largescale automated synthesis of human functional neuroimaging data. Nat Methods 8, 665-670.

44 Yeo, B.T., Krienen, F.M., Sepulcre, J., Sabuncu, M.R., Lashkari, D., Hollinshead, M., 45 Roffman, J.L., Smoller, J.W., Zollei, L., Polimeni, J.R., et al. (2011). The organization of the 46 human cerebral cortex estimated by intrinsic functional connectivity. J Neurophysiol 106, 47 1125-1165.

48 Zaki, J., Weber, J., Bolger, N., and Ochsner, K. (2009). The neural bases of empathic 49 accuracy. Proc Natl Acad Sci U S A 106, 11382-11387. 